\title{
Sleep modulates alcohol toxicity in Drosophila
}

Eric J. Noakes*, Aliza K. De Nobrega*, Alana P. Mellers, and Lisa C. Lyons

Department of Biological Science, Program in Neuroscience, Florida State University,

Tallahassee, FL 32306

\section{Corresponding Author with complete address:}

Lisa C. Lyons

Department of Biological Science

Florida State University

319 Stadium Drive

Tallahassee, FL 32306-4295

Phone: (850) 645-8255

E-mail: 1yons@bio.fsu.edu

Acknowledgements: This work was supported by the National Institutes of Health, National Institute on Alcohol Abuse and Alcoholism grant R21AA021233.

*These authors contributed equally

Present Address EJN: 


\begin{abstract}
Study Objectives: Alcohol abuse is a significant public health problem, particularly in populations in which sleep deprivation is common as such as shift workers and aged individuals. Although research demonstrates the effect of alcohol on sleep, little is known about the role of sleep in alcohol sensitivity and toxicity. We investigated sleep as a factor modulating alcohol toxicity using Drosophila melanogaster, a model system ideal for studies of sleep, alcohol and aging.

Methods: Following 24 hours of sleep deprivation using mechanical stimulation, Drosophila were exposed to binge-like alcohol exposures. Behavioral sensitivity, tolerance, and mortality were assessed. The effects of chronic sleep deprivation on alcohol toxicity were investigated using a short sleep mutant insomniac. Pharmacological induction of sleep for prior to alcohol exposure was accomplished using a $\mathrm{GABA}_{\mathrm{A}}$-receptor agonist, 4,5,6,7-tetrahydroisoxazolo(5,4-c)pyridin-3-ol (THIP) to determine if increased sleep mitigated the effects of alcohol toxicity on middle-aged flies and flies with environmentally disrupted circadian clocks mimicking groups more vulnerable to the effects of alcohol.
\end{abstract}

Results: Acute sleep deprivation increased alcohol-induced mortality following alcohol exposure. However, sleep deprivation had no effect on alcohol absorbance or clearance. Sleep deprivation also abolished functional tolerance measured 24 hours after the initial alcohol exposure, although tolerance at $4 \mathrm{~h}$ was observed. Pharmacologically increasing sleep prior to alcohol exposure decreased alcoholinduced mortality.

Conclusions: Sleep quantity prior to alcohol exposure affects alcohol toxicity with decreased sleep increasing alcohol toxicity and dampened 24-hour alcohol tolerance. In contrast, increased sleep mitigated alcohol-induced mortality even in vulnerable groups such as aging flies and those with circadian dysfunction.

Keywords: Drosophila, sleep deprivation, alcohol, sedation, tolerance, toxicity, neural plasticity 


\section{Statement of significance}

With the growing incidence of sleep deprivation and sleep disorders across adolescents and adults, it is important to understand the role of sleep in alcohol toxicity to develop future therapies for prevention and treatment of alcohol-induced pathologies. Using Drosophila melanogaster, an established model for both sleep and alcohol research, we found that acute and chronic sleep deprivation increased alcohol toxicity and eliminated long-term functional alcohol tolerance. In contrast, increased sleep prior to binge-like alcohol exposure mitigated alcohol-induced mortality even in vulnerable groups with higher susceptibility to alcohol toxicity. 


\section{Introduction}

Alcohol abuse and its associated pathologies is a pervasive societal problem with serious negative impacts on individual health, family structure and the economy ${ }^{1-8}$. In the United States alcohol use disorders account for $79 \%$ of all diagnoses of substance use disorders ${ }^{9}$ and the economic impact of alcohol misuse is estimated at $\$ 249$ billion annually ${ }^{7,10}$. Alcohol abuse and alcohol pathologies appear higher in populations in which sleep deprivation is common including teenagers, young adults, shift workers and aged individuals ${ }^{11-18}$. Although considerable behavioral research has demonstrated the effects of alcohol on sleep homeostasis $^{19-21}$, surprisingly little is known about the role of sleep in modulating alcohol sensitivity and toxicity at the physiological level. Sleep impairments are traditionally viewed as symptoms of alcohol use disorders; however, sleep disorders increase the incidence and risk of relapse in recovering alcoholics ${ }^{22-25}$. Sleep deprivation represents a significant rising public health problem in the United States and the world ${ }^{26-29}$. The pervasiveness of factors contributing to sleep disruptions including artificial light at night, the use of personal electronics and the increase in shiftwork and extended work days $^{30,31}$, combined with the increased risk of substance abuse associated with sleep deprivation, makes understanding how sleep deprivation affects alcohol-induced behaviors and toxicity imperative to identify and optimize therapies for future prevention and treatment of alcohol-induced pathologies.

The high degree of physiological, molecular and neurological conservation between the fruit fly Drosophila melanogaster and mammals makes Drosophila an ideal model for the investigation of sleep and alcohol interactions ${ }^{32-34}$. Sleep in Drosophila occurs in stages, varying in intensity during the night with observable sex and age dependent differences ${ }^{35-44}$. As in other species, circadian and homeostatic processes regulate sleep in flies with waking activity affecting sleep need ${ }^{38,45}$. Moreover, alcohol physiology is remarkably conserved from flies to humans with parallels in behaviors as well as the underlying molecular mechanisms ${ }^{46,47}$. When exposed to alcohol vapor, initially flies exhibit hyperactivity with increased locomotor activity, followed by a loss of motor control and eventually sedation ${ }^{48-51}$. Flies also develop functional alcohol tolerance dependent upon changes in neural plasticity ${ }^{50,52-55}$ and addictionlike behaviors ${ }^{56-58}$ with a preference for alcohol following previous exposure ${ }^{59,60}$. 
We investigated the role of decreased and increased sleep in modulating alcohol toxicity. We found that acute sleep deprivation increased behavioral sensitivity and mortality following acute and repeated exposure to alcohol. These effects were independent of alcohol metabolism as no differences were observed in alcohol absorption and clearance between sleep deprived and non-sleep deprived flies. Sleep deprivation also inhibited the induction of long-term functional alcohol tolerance observed $24 \mathrm{~h}$ following the first alcohol exposure, although short-term tolerance measured $4 \mathrm{~h}$ following the first alcohol exposure was not affected. Chronic sleep restriction also increased alcohol-induced mortality. Encouragingly, we found that pharmacologically increasing sleep had the opposite effect of sleep deprivation, ameliorating alcohol mortality in middle-aged flies and flies with a disrupted circadian clock. This research highlights the critical role of sleep as a factor in alcohol toxicity.

\section{Methods}

\section{Fly Maintenance}

All flies were maintained on standard cornmeal-molasses food at $25^{\circ} \mathrm{C}$ and $60-70 \%$ relative humidity in 12:12 light-dark (LD) cycles. Insomniac (inc) mutants and the background $w^{1118}$ line were generously provided by Dr. Nicholas Stavropoulos, New York University. Adult flies ( $\sim 30$ per vial) were transferred approximately every 3 days to maintain stress-free cultures. All experiments were carried out in an environmentally controlled dark room at $25^{\circ} \mathrm{C}$ and $60-70 \%$ relative humidity under dim red light. Zeitgeber time (ZT) 0 represents lights on and ZT 12 corresponds with lights off. For experiments performed in constant light (LL) conditions, flies were transferred to LL on the day of eclosion.

\section{Alcohol Exposure}

Alcohol vapor exposure was performed as previously described ${ }^{51,61,62}$. Four tubes, each containing $\sim 30$ flies, received a steady flow of ethanol vapor at a pre-determined percentage. Precise alcohol percentages were achieved by mixing air bubbled through deionized water and 95\% ethanol (Koptec, Declon Labs, Inc.). Air flow rates were monitored throughout the experiment to ensure consistency of alcohol 
concentration. Water vapor controls were run simultaneously with $100 \%$ water vapor. Alcohol exposures were performed at ZT 9 to avoid circadian variation in responses unless otherwise stated for a specific protocol.

\section{Sleep Deprivation}

Consistent sleep deprivation was achieved using gentle mechanical stimulation on the GyroMini Nutating Mixer (Labnet International, Inc.). Vials containing $\sim 30$ flies were placed at an angled position in a larger beaker with a raised block at a fixed position inside the beaker. Mixer rotation caused the vials to rotate within the beaker and then gently jump over the raised block, providing the flies with a startle movement every 2.5 seconds. The constant motion of the vials combined with the startle ensured consistent sleep deprivation with no apparent injuries or increased mortality observed after 24 hours of sleep deprivation. Sleep deprivation was performed in an incubator under $25^{\circ} \mathrm{C}, 60-70 \%$ relative humidity and $12: 12 \mathrm{LD}$ conditions. Non-sleep deprived controls were housed in the same incubator.

\section{Sedation}

Alcohol-induced sedation was performed as previously described ${ }^{48}$. Briefly, flies were exposed to $50 \%$ alcohol vapor for one hour with observations of behavioral state made every five minutes following a gentle tap of the vial. Flies were scored as sedated when immobile and lacking coordinated leg movements except for spontaneous twitching ${ }^{52}$. The mean time to $50 \%$ sedation was calculated using a linear extrapolation.

\section{Tolerance}

Tolerance was determined as previously described ${ }^{51}$. Flies received a pre-exposure of $50 \%$ alcohol for 30 minutes at ZT4.5 following a one-hour dark room acclimation period. Sedation was assessed during the pre-exposure. Flies were then returned to food vials to allow time for recovery and complete metabolism of the alcohol before testing. Testing occurred 4 hours later at ZT9 for short-term rapid tolerance or 24 hours later for long-term rapid tolerance with all experimental groups represented at each test. Tolerance was defined as an increase in average time to reach $50 \%$ sedation from the pre-exposure with the 
difference in sedation time between naïve and pre-exposed flies used for quantification. For tolerance experiments, sleep deprivation took place from ZT3.5 - ZT3.5.

\section{Mortality}

Following each alcohol exposure, flies were returned to food vials placed horizontally for approximately $2 \mathrm{~h}$ to allow recovery of postural control. Immediate mortality was assessed 24 hours following the last alcohol exposure and then daily for 6 days. Delayed mortality refers to the cumulative mortality within seven days of the final alcohol exposure.

\section{Gaboxadol Treatment}

Sleep was pharmacologically increased with the GABA-A agonist, 4,5,6,7-tetrahydroisoxazolo [5,4c]pyridin-3-ol (THIP or Gaboxadol). $10 \mathrm{~d}$ old (in constant light) or $20 \mathrm{~d}$ old (in LD) flies were transferred to Gaboxadol-containing food $(0.05 \mathrm{mg} / \mathrm{mL})$ for either 48 or $24 \mathrm{~h}$ respectively prior to repeated alcohol exposure. A repetitive alcohol exposure protocol was used to assess alcohol-induced mortality as described previously ${ }^{61}$. Flies were exposed for 3 days to $1 \mathrm{~h}$ alcohol vapor at ZT 9 (exposures separated by $24 \mathrm{~h})$.

\section{Alcohol Absorbance}

Following $24 \mathrm{~h}$ sleep deprivation, batches of 20 flies were exposed to $50 \%$ alcohol vapor for 30 minutes at ZT 9, after which they were frozen at $0,0.5,1,2$, or $4 \mathrm{~h}$ following alcohol exposure. Alcohol absorbance was measured using an enzymatic alcohol dehydrogenase assay (ADH-NAD kit; SigmaAldrich) per the manufacturer's directions and as described previously ${ }^{49,51}$. Briefly, flies were homogenized in $200 \mathrm{uL}$ refrigerated Tris- $\mathrm{HCl}(\mathrm{pH} 7.5)$ buffer. Homogenate was spun at $15,000 \mathrm{x}$ g for 20 min at $4{ }^{\circ} \mathrm{C} .250 \mathrm{uL}$ NAD-ADH reagent was added to a $5-\mu \mathrm{L}$ aliquot of supernatant. Absorbance was measured at $340 \mathrm{~nm}$ within 20 min using a 96-well plate format and a Versa-Max plate reader (brand). Alcohol absorbance was normalized to total protein to eliminate the effect of body size variation between batches of flies.

\section{Locomotor Activity Rhythms}


Locomotor activity of adult male flies was monitored using Drosophila activity monitors (Trikinetics, Waltham, MA) as described previously ${ }^{63}$. Sleep activity of flies was recorded following entrainment either in $\mathrm{LL}$ or $\mathrm{LD}$ cycles at $25^{\circ} \mathrm{C}$ for 4 days, after which the flies were transferred without using anesthetic to Gaboxadol-containing media for 48 hours for further measurements. Sleep data were analyzed using the ClockLab Suite.

\section{Statistics}

Statistics were performed using GraphPad Prism Version 6.0. Experimental groups were compared using analysis of variance (ANOVA). Post-hoc analyses in multiple comparisons were performed using the Bonferroni correction.

\section{Results}

\section{Sleep deprivation increases sensitivity to alcohol-induced sedation}

Sleep deprivation appears to be a contributing factor to the increased use of alcohol as suggested in studies of shift workers and young adults ${ }^{64-69}$. However, relatively little is known about the effects of sleep deprivation on alcohol toxicity and alcohol pathologies. As a first step in exploring the modulatory role of sleep on alcohol sensitivity, we evaluated the effect of 24 hours sleep loss on alcohol sensitivity. Drosophila (mixed sex, $10 \mathrm{~d}$ old) were sleep deprived using mechanical sleep deprivation for 24 hours (ZT 8 - ZT 8) and then exposed to 50\% alcohol vapor (1 h exposure; Figure 1A). As predicted given the sedative effects of alcohol, sleep deprived flies were sedated significantly faster than non-sleep deprived age-matched controls indicating that sleep loss increases behavioral sensitivity to alcohol (Figure 1B $\left.1 \mathrm{C} ; t_{(14)}=13.46, p=0.0002\right)$.

Potentially, the alteration in alcohol sensitivity between the groups may have arisen from the mechanical procedure used for sleep deprivation rather than sleep deprivation itself. To test whether sleep deprivation or mechanically induced stress was the underlying cause of the observed difference in alcohol sensitivity, we took advantage of the sex-specific difference in daytime sleep in flies ${ }^{38}$. Male flies exhibit a daytime "siesta sleep" period in which they sleep significantly more during the daytime as compared to 
mated females ${ }^{70}$. If the increased behavioral alcohol sensitivity observed in sleep deprived flies was attributed to sleep loss, sleep deprivation during the daytime should have a greater impact on males. However, if the increased sensitivity to alcohol were due to mechanically induced stress, the effects of daytime sleep deprivation would be similar in males and females. Mated 10-d old female and male flies were separately sleep deprived for the first eight hours of the subjective day (ZT $0-$ ZT 8) and exposed to $50 \%$ alcohol vapor for $1 \mathrm{~h}$ at ZT 9 with sedation assayed at $5 \mathrm{~min}$ intervals. Sleep deprived males were significantly more sensitive to alcohol than non-sleep deprived males with shorter exposure times inducing sedation (Figure 1D - 1E; ANOVA: $F_{3,28}=29.24, p<0.0001$ ). In contrast, sleep deprivation appeared to have little effect on female flies with sleep deprived females showing similar alcohol responses to non-sleep deprived flies (Figure 1D - 1E; ANOVA: $F_{3,28}=29.24, p<0.0001$ ). These results suggest that sleep deprivation increases the behavioral sensitivity to alcohol and these effects are independent of any stress from mechanical perturbation.

\section{Sleep deprivation increases acute and chronic alcohol toxicity}

Excessive binge drinking escalates the incidence of alcohol-poisoning deaths ${ }^{71,72}$. Therefore, it is important to understand the potential confounding effects of sleep loss on alcohol toxicity. To determine whether sleep deprivation alters alcohol toxicity, we tested the effect of a single exposure to $50 \%$ alcohol vapor on mortality. Flies (10 d, mixed sex) were sleep deprived for $24 \mathrm{~h}(\mathrm{ZT} 8-\mathrm{ZT} 8)$ and exposed to $50 \%$ alcohol vapor for one h at ZT 9 (Figure 2A). Nearly 100\% of the flies become sedated under this protocol. Mortality was assessed $24 \mathrm{~h}$ and 7 days following alcohol exposure. When exposed to alcohol vapor following sleep deprivation, flies showed significant mortality $24 \mathrm{~h}$ after alcohol exposure compared to non-sleep deprived flies exposed to alcohol vapor or flies that were sleep deprived and exposed to water vapor (Figure 2B, ANOVA: $F_{3,28}=22.50, p<0.0001$ and 2C; ANOVA: $F_{3,28}=14.01, p$ $<0.0001)$. However, there was no significant further increase in alcohol induced mortality when cumulative delayed mortality was measured 7 days following the exposure to alcohol suggesting that the effects of sleep deprivation on alcohol toxicity occurred within the first 24 hours. Non-sleep deprived and sleep deprived flies exposed to water vapor alone had negligible levels of mortality at either $24 \mathrm{~h}$ or 7 
days suggesting that $24 \mathrm{~h}$ sleep deprivation itself does not result in mortal injury to the flies (Figure 2B and 2C). Exposure to alcohol vapor caused a noticeable but not significant rise in immediate and delayed mortality compared to water vapor controls (Figure 2B and C). These results suggest that sleep deprivation exacerbates the acute toxicity of alcohol with primary mortality observed within 24 hours of alcohol exposure (Figure 2B). We next investigated the effects sleep deprivation prior to a repeat binge alcohol exposure paradigm. As previously, flies were sleep deprived for $24 \mathrm{~h}$ (ZT 8 - ZT 8) and then exposed to $40 \%$ alcohol vapor for $1 \mathrm{~h}$ (ZT 9) on 3 consecutive days (Figure 2D). Perhaps not surprisingly, the first alcohol exposure after sleep deprivation induced a significant increase in mortality (Figure 2E, ANOVA: $\left.F_{3,76}=15.42, p<0.0001\right)$. Alcohol-induced mortality was not significantly higher following the $2^{\text {nd }}$ and $3^{\text {rd }}$ alcohol exposures (Figure $2 \mathrm{~F}$ ), potentially due to the opportunity for recovery sleep following the $1^{\text {st }}$ exposure to alcohol. The degree of mortality observed 7 days following the last alcohol exposure was similar between the acute and repeated binge alcohol paradigms (Figure 2G, ANOVA: $F_{3,76}=19.91$, $p<0.0001)$.

\section{Sleep deprivation does not affect the rate of alcohol clearance}

It is possible that the increases in alcohol sensitivity and mortality observed following sleep deprivation were due to increased alcohol absorption or a decline in the rate of alcohol clearance resulting in greater alcohol exposure and subsequent toxicity. To investigate this possibility, flies were sleep deprived as previously described and exposed to 50\% alcohol vapor for $30 \mathrm{~min}$ at ZT 9 and alcohol absorbance was measured (Figure 3A). There were no significant differences in alcohol absorbance or clearance between sleep deprived flies and non-sleep deprived flies (Figure 3B). These results suggest that potential metabolic changes due to sleep deprivation do not account for the observed increased sensitivity to alcohol with the more likely possibilities including sleep deprivation induced changes in neuroadaptation at the molecular or cellular levels.

\section{Chronic sleep deprivation induces increased alcohol-induced mortality}

Chronic sleep deprivation with multiple short sleep nights may also be a predisposing factor for increased alcohol consumption and other recreational drug use ${ }^{18,73}$. In the United States, approximately 70 million 
Americans suffer from chronic sleep loss with serious consequences for health and longevity as well as economic productivity ${ }^{29,74,75}$. To investigate the effects of chronic sleep restriction on alcohol neurobiology, we used a genetic approach rather than a mechanical system to induce sleep deprivation to avoid the possibility of stress arising from long-term mechanical stimulation. Numerous mutants with short sleep phenotypes have been identified in Drosophila. However, the circadian clock also regulates aspects of sleep and sleep timing, and many sleep mutants have circadian phenotypes. Given previous research demonstrating circadian modulation of alcohol sensitivity and increased alcohol-induced mortality with circadian disruption ${ }^{48,61}$, we used the mutant insomniac that has normal circadian rhythms but exhibits a short sleep phenotype ${ }^{76}$ to investigate the effects of chronic sleep restriction on alcohol toxicity. Insomniac (inc) is a mutation in a putative adaptor protein for the Cullin-3 ubiquitin ligase complex $^{76}$. We used two inc mutant lines, $i n c^{1}$ and $i n c^{2}$ (generous gifts of Nicholas Stavropoulos at NYU), to test the effects of chronic sleep restriction on alcohol sensitivity and alcohol-induced mortality. Both inc ${ }^{l}$ and inc 2 mutant lines have a $90 \%$ reduction in inc transcript mRNA levels with no detectable protein produced $^{76}$. Confirming previously published results, we found that that $i n c^{l}$ and $i n c^{2}$ flies (Figure $4 \mathrm{~A}-\mathrm{C}$ ) exhibit considerable reductions in total sleep time with $i n c^{l}$ flies sleeping a little over 300 minutes per day and $i n c^{2}$ flies sleeping approximately $600 \mathrm{~min}$ per day (Figure 4A, ANOVA: $F_{2,67}=$ 81.13, $p<0.0001$ ). These mutants exhibit significantly shortened sleep bouts (Figure 4B, ANOVA: $F_{2,67}=$ $17.52, p<0.0001)$ reflecting a decrease in sleep consolidation, although they do have a greater number of sleep bouts (Figure 4C, ANOVA: $F_{2,67}=8.64, p<0.0001$ ).

To investigate the effects of chronic sleep restriction on alcohol sensitivity, we exposed $10 \mathrm{~d}$ old $i n c^{1}$ and $i n c^{2}$ flies to 50\% alcohol for $1 \mathrm{~h}$ at ZT 9 with sedation assessed at 5-minute intervals (Figure 4D). Surprisingly, $i n c^{1}$ and $i n c^{2}$ flies did not exhibit increased sensitivity to alcohol; indeed, these mutants were more resistant to the sedating effects of alcohol with significantly longer times to reach $50 \%$ sedation than the $w^{1118}$ control flies (Figure 4D and 4E, ANOVA: $F_{2,34}=47.28, p<0.0001$ with post-hoc analysis identifying significant differences between $w^{1118}$ vs. $i n c^{1}$ and $w^{1118}$ vs $i n c^{2}$ ). These results suggest that either compensatory mechanisms exist to buffer against increased sensitivity to alcohol in these mutants 
or chronic sleep loss associated with the disruption of the Cullin-3 ubiquitin ligase complex does not increase alcohol sensitivity.

While the chronic sleep deficit associated with the disruption of the Cullin-3 ubiquitin ligase complex in the inc mutants did not increase alcohol sensitivity, we hypothesized that it would still increase alcohol toxicity as alcohol affects multiple signaling pathways both in the central nervous system and in peripheral tissues. To test this, we gave $10 \mathrm{~d} i n c^{l}$ and $i n c^{2}$ flies a single exposure to $50 \%$ alcohol vapor for $1 \mathrm{~h}$ at ZT 9 and assessed mortality $24 \mathrm{~h}$ and $7 \mathrm{~d}$ following the alcohol exposure. Both $i n c^{1}$ and $i n c^{2}$ flies exhibited significantly higher mortality immediately ( $24 \mathrm{~h}$ ) and $7 \mathrm{~d}$ following the exposure compared to $w^{1118}$ background controls (Figure 5B, ANOVA: $F_{2,29}=16.46, p<0.0001$ and Figure 5C, ANOVA: $F_{2,29}=20.87, p<0.0001$ ). Given that the inc mutants are postulated to have defects in ubiquitination that may affect many target proteins and signaling pathways, it is possible that the observed mortality was due to other consequences of the mutation and not to the effects of chronic sleep restriction on alcohol toxicity. Presumably as inc flies age, the short sleep phenotype results in an accumulated sleep debt. If this is the case, we hypothesized that younger flies $(3 \mathrm{~d})$ would show lower alcohol-induced mortality at levels similar to that seen with acute sleep deprivation. To test this hypothesis, we exposed $3 \mathrm{~d} i n c^{l}$ and $i n c^{2}$ flies to alcohol and assessed mortality $24 \mathrm{~h}$ and $7 \mathrm{~d}$ following exposure. While there was higher mortality observed in $3 \mathrm{~d} i n c^{l}$ and $i n c^{2}$ flies following alcohol exposure than $3 \mathrm{~d} w^{1118}$ control flies (Figure 5E, ANOVA: $F_{2,34}=15.03, p<0.0001$ and Figure 5F, ANOVA: $F_{2,34}=$ 25.01, $p<0.0001$ ), the $3 \mathrm{~d} i n c^{1}$ and $i n c^{2}$ flies exhibited significantly lower mortality following a single exposure to alcohol than $10 \mathrm{~d} i n c^{1}$ and $i n c^{2}$ flies (Figure 5E - F). No significant differences were observed in alcohol-induced mortality between $3 \mathrm{~d}$ and $10 \mathrm{~d} w^{1118}$ flies. These results suggest that the increase in alcohol-induced mortality in the $10 \mathrm{~d}$ inc mutants was due to the accrued sleep debt in the older flies rather than a non-sleep related consequence of the mutation. Together, these results suggest that separate mechanisms mediate the behavioral sensitivity to alcohol and the alcohol's toxic effects whereby insomniac is necessary for the resistance to alcohol-induced mortality but not alcohol behavioral sensitivity. 
Pharmacologically increasing sleep ameliorates alcohol-induced mortality in populations with sleep phenotypes

Previously we found that circadian arrhythmia and aging significantly increase alcohol-induced mortality ${ }^{61}$ mirroring human populations such as shift-workers and the elderly with sleep disturbances. If accrued sleep loss is the driving force for the observed alcohol-induced mortality in inc mutants, we hypothesized that increasing sleep in the $i n c^{l}$ and $i n c^{2}$ mutants should decrease mortality following exposure to alcohol. To pharmacologically increase sleep, $i n c^{1}$ and $i n c^{2}$ mutant flies were raised on

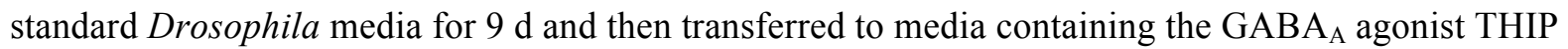
which has previously been shown to pharmacologically increase sleep in Drosophila ${ }^{77-79}$. Following THIP exposure, $i n c^{l}$ and $i n c^{2}$ flies were given a single $1 \mathrm{~h}$ exposure to alcohol (Figure 6A). THIP exposure significantly reduced mortality $24 \mathrm{~h}$ and $7 \mathrm{~d}$ following alcohol exposure in both $i n c^{1}$ and $i n c^{2}$ mutant flies compared to non-THIP exposed $i n c^{1}$ and $i n c^{2}$ mutants (Figure 6B, ANOVA: $F_{3,44}=13.27, p<$ 0.0001 and Figure 6C, ANOVA: $F_{2,44}=12.83, p<0.0001$ respectively). However, THIP has dual effects as an analgesic and anxiolytic, and has been tested as a treatment for both alcohol use disorders as well as insomnia ${ }^{80}$. Potentially, as an agonist for $\mathrm{GABA}_{\mathrm{A}}$ receptors, THIP may be affecting alcohol-receptor interactions to affect mortality rather than through its pharmacological induction of sleep. To determine whether acute THIP interactions decreased alcohol-induced mortality by altering alcohol-receptor interactions rather than through increased sleep prior to alcohol exposure, we fed $10 \mathrm{~d} i n c^{1}, i n c^{2}$ and $w^{1118}$ flies $0.1 \mathrm{mg} / \mathrm{mL}$ THIP for $1 \mathrm{~h}$ at ZT 7-8 and then exposed them to $50 \%$ alcohol vapor. There were no differences in mortality between THIP-fed $i n c^{l}$ and $i n c^{2}$ flies and non-THIP fed flies following alcohol exposure (Figure 6E, ANOVA: $F_{5,46}=50.88, p<0.0001$ and Figure 6F, ANOVA: $F_{5,46}=55.83, p<$ 0.0001). These results are consistent with the hypothesis that increased sleep prior to binge-like alcohol exposure buffers the toxic effects of alcohol.

\section{Pharmacologically increasing sleep, independent of circadian rhythmicity, decreases alcohol-}


In Drosophila, the circadian clock can be rendered non-functional using environmental manipulation by housing the flies in constant light. Constant light (LL) is sufficient to dampen molecular oscillations and abolish circadian rhythms in locomotor activity, memory formation and the rhythm in alcohol-induced loss-of-righting reflex ${ }^{51,63,81-85}$. We have previously shown environmental disruption of circadian function exacerbates alcohol sensitivity and mortality ${ }^{48,61}$. Along with a disrupted circadian clock, we found that $10 \mathrm{~d}$ CS flies in LL have significantly lower total sleep, specifically less sleep during the subjective night compared to $10 \mathrm{~d}$ CS flies in LD (Figure $7 \mathrm{~A} ; t_{(236)}=4.46, p<0.0001$ ) and Figure 7B, ANOVA: $\left.F_{3,442}=27.31, p<0.0001\right)$, consistent with mis-timed sleep due to circadian dysfunction. Flies housed in LL had significantly higher number of sleep bouts in both the subjective day and night (Figure 7C, ANOVA: $F_{3,442}=98.99, p<0.0001$ ), although the sleep bout length was significantly shorter than flies housed in LD resulting in the decrease in total sleep (Figure 7D, ANOVA: $F_{3,442}=78.45, p<$ 0.0001). As a first step to separate the effects of sleep from the effects of circadian disruption on alcohol toxicity, we characterized the effects of THIP on sleep for flies housed in LL. As expected, flies housed on THIP containing food in constant light slept significantly more than flies on regular Drosophila food in LL (Figure 7E - H; Mean sleep time per day: $t_{(233)}=29.43, p<0.0001$; Mean sleep time, day vs night, ANOVA: $F_{3,463}=437.1, p<0.0001$; number of sleep bouts, ANOVA: $F_{3,463}=358.1, p<0.0001$; Mean sleep bout length, ANOVA: $\left.F_{3,463}=277.6, p<0.0001\right)$. To separate the role of sleep from circadian regulation in mediating alcohol toxicity following a repeat binge-like alcohol exposure, we increased sleep in flies in LL as they remained under conditions of circadian disruption. $10 \mathrm{~d}$ LL flies were maintained on medium containing THIP for 48 hours prior to exposure to the first of three exposures of $40 \%$ alcohol vapor (Figure 7I). LL flies housed on THIP containing food prior to alcohol exposure had a significantly lower mortality rate than those exposed to alcohol vapor alone (Figure $7 \mathrm{~J}$, ANOVA: $F_{3,36}=$ 132.6, $p<0.0001)$. However, LL flies given a short exposure to THIP followed by alcohol exposure exhibited no differences in mortality compared to LL flies exposed to alcohol alone (Figure 7K, ANOVA: $\left.F_{3,36}=92.26, p<0.0001\right)$. These results suggest that increased sleep is sufficient to ameliorate mortality following repeated binge-like alcohol exposure even under conditions of circadian disruption. 


\section{Increasing sleep buffers age-related susceptibility to alcohol-induced mortality}

Aging is accompanied by the breakdown of circadian rhythmicity at the cellular, metabolic and physiological levels as well as disruptions in sleep architecture ${ }^{61,86-90}$. In recent years, chronic and binge alcohol consumption in middle-aged and older adults has significantly increased ${ }^{91,92}$ with more than $75 \%$ of the alcohol-induced poisoning deaths occurring in these age groups ${ }^{11,14}$. More than $10 \%$ of older adults engage in binge drinking behavior ${ }^{91}$. Given that the aging population is expected to double by $2050^{93}$, it is necessary to identify ways to treat or ameliorate alcohol toxicity in middle-aged and older individuals. In previous studies, we have shown that aging exacerbates alcohol sensitivity and mortality ${ }^{61}$. Middle-aged flies $(20 \mathrm{~d})$ exhibit shorter sleep times compared to younger flies $\left({ }^{40}\right.$; Figure $8 \mathrm{~A},\left(t_{(147)}=6.54, p<0.0001\right)$ and Figure 8B, ANOVA: $\left.F_{3,294}=38.12, p<0.0001\right)$. While we found no differences in total sleep amount during the night between 10 and $20 \mathrm{~d}$ flies, $20 \mathrm{~d}$ flies had a significantly greater number of sleep bouts with shorter duration reflecting decreases in sleep consolidation (Figure 8C, ANOVA: $F_{3,294}=19.21, p<$ 0.0001 and Figure 8D; ANOVA: $\left.F_{3,294}=38.12, p<0.0001\right)$. We tested whether pharmacologically increasing sleep in middle-age was sufficient to overcome the age-related increase in mortality following repeated binge-like exposures to alcohol. We pharmacologically induced sleep in $20 \mathrm{~d}$ CS flies by housing them on $0.1 \mathrm{mg} / \mathrm{mL}$ THIP for $24 \mathrm{~h}$ after which they were given a $1 \mathrm{~h}$ alcohol exposure for 3 consecutive days (Figure 8I). 20 d THIP-fed flies slept significantly more than control $20 \mathrm{~d}$ flies (Figure $8 \mathrm{E}-8 \mathrm{H} ;$ Avg total sleep/day: $t_{(89)}=13.05, p<0.0001$; Avg sleep time, day vs night, ANOVA: $F_{3,178}=$ 91.72, $p<0.0001$; number of sleep bouts, ANOVA: $F_{3,178}=60.24, p<0.0001$; Sleep bout length, ANOVA: $\left.F_{3,178}=113.0, p<0.0001\right)$. Middle-aged flies housed on THIP containing food prior to the repeated binge-like alcohol exposures had significantly lower rates of mortality than those exposed to alcohol alone (Figure 8J, ANOVA: $F_{3,44}=243.8, p<0.0001$ ). The decreased mortality observed in THIPfed flies was not due to increased alcohol tolerance from THIP interactions as $20 \mathrm{~d}$ flies given THIP for 1 $\mathrm{h}$ at ZT 7 followed by alcohol exposure at ZT 9 show mortality rates similar to $20 \mathrm{~d}$ flies exposed to alcohol alone (Figure 8K, ANOVA: $F_{3,30}=23.09, p<0.0001$ ). These results suggest that increased sleep 
is sufficient to ameliorate mortality following repeated alcohol exposures in middle-aged flies that have both circadian and sleep disruption.

\section{Sleep deprivation inhibits long-term but not short-term tolerance}

Drosophila exhibit drug tolerance with repeat alcohol exposures in which the behavioral response to subsequent exposures of alcohol is lessened similar to that observed in rodent models and humans. At the behavioral level, functional tolerance results in a decreased sensitivity to alcohol during subsequent exposures with increased alcohol concentrations or longer alcohol exposures necessary to induce sedation $^{33,94,95}$. In flies, rapid tolerance develops after a single alcohol exposure and can be observed during a second alcohol exposure $4 \mathrm{~h}$ or $24 \mathrm{~h}$ later ${ }^{50,96}$. The development of functional alcohol tolerance is dependent upon changes in neural plasticity rather than changes in the metabolism or clearance of alcohol $^{50,53-55,96,97}$. Changes in neural plasticity associated with drug and alcohol tolerance share features in common with synaptic plasticity observed in learning and memory ${ }^{98-100}$. Potentially, sleep loss affects the development of alcohol tolerance as sleep deprivation disturbs memory formation as seen across invertebrate and vertebrate species ${ }^{101-103}$. To investigate the effect of sleep deprivation on tolerance formed after a single alcohol exposure, $10 \mathrm{~d}$ wild-type flies were sleep deprived for 24 hours (ZT 3.5 ZT 3.5) and given a pre-exposure of 50\% alcohol vapor for 30 minutes (ZT 4.5; Figure 9A). Pre-exposed sleep deprived flies and sleep deprived naïve flies were exposed to alcohol $4 \mathrm{~h}$ later at ZT 9 during which sedation was measured (Figure 9A). Similarly, non-sleep deprived flies were pre-exposed to alcohol with responses compared during a second alcohol exposure to naïve flies. Non-sleep deprived flies demonstrated robust $4 \mathrm{~h}$ alcohol tolerance with significant increases observed in the time necessary for $50 \%$ of the flies to reach sedation compared to naïve flies (Figure 9B, ANOVA: $F_{3,20}=49.62, p<0.0001$ and Figure 9C). Surprisingly, sleep deprived flies also demonstrated robust $4 \mathrm{~h}$ alcohol tolerance (Figure 9B and C) suggesting that sleep disruption does not affect the cellular signaling mechanisms necessary for the formation of $4 \mathrm{~h}$ tolerance.

To determine the effect of sleep deprivation on the formation of long-term alcohol tolerance, flies were sleep deprived for 24 hours (ZT 7.5 - ZT 7.5) and given a pre-exposure of 50\% alcohol vapor for 30 
minutes (ZT 8.5) and tested 24 hours later at ZT 9 (Figure 9D). Groups of non-sleep deprived flies were handled concurrently. When flies were tested $24 \mathrm{~h}$ after the initial alcohol exposure, sleep-deprived flies demonstrated significantly less tolerance to alcohol with the time to sedation similar to sleep-deprived naïve flies while non-sleep deprived flies demonstrated robust long-term tolerance with response times significantly different than naïve flies (Figure 9E, ANOVA: $F_{3,26}=125.7, p<0.0001$ and Figure 9F). Although our previous research found that tolerance was not modulated by the circadian clock, we verified the effect on long-term tolerance by exposing flies to alcohol at the same time that we observed the formation of $4 \mathrm{~h}$ tolerance in sleep-deprived flies (Figure 9G). Sleep-deprived flies pre-exposed to alcohol at ZT 8.5 and then subsequently exposed to alcohol at ZT 9 the following day also exhibited little or no alcohol tolerance, while non-sleep deprived flies exhibited significant long-term tolerance (Figure 9H, ANOVA: $F_{3,20}=0.92, p=0.4488$ and Figure 9I). Thus, acute sleep deprivation prior to alcohol exposure inhibits the expression of alcohol tolerance $24 \mathrm{~h}$ following the initial alcohol pre-exposure while no effect is observed on the development of short-term tolerance expressed $4 \mathrm{~h}$ after the initial exposure. These results are consistent with the hypothesis that different molecular mechanisms underlie the development of short-term and long-term rapid alcohol tolerance similar to the differences in formation of short and long-term memory.

\section{Discussion}

Research from our lab and others suggests a bidirectional relationship between clock dysfunction and the onset and severity of alcohol-related pathologies ${ }^{18,48,51,104,105}$. Social jet lag, large shifts in sleep timing between the weekday and the weekend is observed in numerous populations, including individuals on shift and rotating schedules ${ }^{106,107}$ and is strongly correlated with increased alcohol use ${ }^{108,109}$. Due to the long working hours, rotating schedules and work-associated stress, many individuals report using alcohol as a sleep aid ${ }^{64,65,110,111}$ which can eventually lead to an increased number of binge drinking episodes and other detrimental effects associated with alcohol abuse $\mathrm{f}^{64,65,67,112}$. Previous studies from our lab found that the circadian clock modulates alcohol sensitivity and toxicity and that circadian dysfunction significantly increases the behavioral sensitivity to alcohol and mortality following acute and repeated alcohol 
exposures $^{48,51}$. In humans, differences in individual chronotype also appears to modulate alcohol use and its associated pathologies. Individuals expressing an "evening chronotype" report significantly increased alcohol use ${ }^{113-124} 125$. Interestingly, individuals with an evening chronotype also have lower quality of sleep and increased greater daytime fatigue ${ }^{126,127}$. However, it has been difficult to detangle the effects of circadian dysfunction from the effects of altered sleep on alcohol use.

Sleep disorders and sleep disturbances have become increasingly prevalent in modern society with longer working hours, irregular work schedules and the prevalence of electronics, affecting more than $35 \%$ of adults and $70 \%$ of teenagers ${ }^{27,74,128-131}$. Insufficient sleep exacerbates the risk of developing chronic diseases and health problems including cancer, diabetes, neurodegenerative and psychiatric disorders ${ }^{132-136}$. Consequently, we investigated the effects of sleep loss on the alcohol sensitivity and toxicity using Drosophila melanogaster to dissect the interactions between sleep deprivation and alcohol sensitivity and mortality.

We found that acute $(24 \mathrm{~h})$ sleep deprivation significantly increased sensitivity and mortality in young flies following a single binge-like exposure to alcohol. Most of the observed increase in mortality following alcohol exposure occurred within $24 \mathrm{~h}$ following alcohol exposure. These effects were independent of stress or injury as $48 \mathrm{~h}$ recovery sleep prior to alcohol minimized alcohol-induced mortality. The increases in sensitivity and mortality were also independent of changes in metabolic tolerance as there were no differences between sleep deprived and non-sleep deprived flies in alcohol absorbance or clearance. Thus, sleep deprivation changes both immediate alcohol sensitivity and acute alcohol toxicity after a single binge-like alcohol exposure. Our data underlines the phylogenetic conservation across species showing a correlation between sleep loss and alcohol behaviors. Studies from rodents and humans outline a correlation between sleep loss and increased severity of alcohol behavioral responses including increased alcohol intake, accelerated development of alcohol abuse, dependence and relapse following alcohol abstinence ${ }^{137-140}$. In mice, alcohol dose dependently increases hyperactive locomotor activity in open-field tests with acute sleep deprivation for $48 \mathrm{~h}$ abolishing these stimulatory effects $^{141}$. Insufficient sleep $(<8 \mathrm{~h}$ per night) is correlated with increased number of drinking sessions in 
adolescents and young adults ${ }^{142-144}$. College-aged students are considered a vulnerable population for risktaking behaviors and multiple studies show a strong correlation between poor sleep quality and excessive alcohol intake and the accompanying consequences for mental health and academic performance including increased rates of depression, anxiety, psychological stress and academic issues in these students $^{66,145,146}$. Insufficient and poor quality sleep also appear to predict the onset of alcohol abuse and its adverse consequences ${ }^{68,147-150}$. Sleep disturbances observed in children 3-5 years of age predicted the early onset of alcohol use at ages $12-14^{151}$. This is particularly harmful because recovering alcoholics who used alcohol as a sleep aid are three times more likely to relapse in 12 months ${ }^{22,23,152}$. Altogether, these studies emphasize disturbed sleep as a potent risk factor for the initiation of alcohol use, escalation of problems associated with alcohol abuse and hindrance of recovery from alcohol-use disorders.

With the genetic tools and mutants available, Drosophila provides a suitable model system to test the relationship between chronic sleep disturbances and alcohol induced pathologies. Using flies with mutations in the insomniac gene (inc) that provide a model mirroring chronic sleep restriction, we found that inc mutants have significantly increased mortality following alcohol exposure than background controls. Moreover, we found that alcohol exposure is more lethal in $10 \mathrm{~d}$ old inc-mutant flies compared to $3 \mathrm{~d}$ old flies, although wild type flies in either age groups show little alcohol-induced mortality. Inc mutant flies were surprisingly less sensitive to the sedative effects of alcohol compared to their background controls supporting previous research that the different physiological consequences of alcohol can be regulated separately. Although, the mechanism through which sleep buffers alcohol toxicity is unknown, it is possible that the changes in oxidative stress in the inc mutant flies may contribute to the change in alcohol toxicity. The inc gene seems necessary for mediating the oxidative stress response as reducing inc both globally and neuronally significantly increases mortality following a single injection to paraquat, a common inducer of oxidative stress ${ }^{76,153}$. Support for this hypothesis is found in previous research demonstrating that pharmacologically increasing sleep in inc-mutant flies using gaboxadol significantly decreased the sensitivity to paraquat-induced oxidative stress ${ }^{153}$. Sleep loss has also been shown to increase reactive oxygen species in the gut ${ }^{154}$ raising the possibility that peripheral 
mechanisms also contribute to increased alcohol toxicity. As changes in sleep potentially impact multiple physiological processes in the central nervous system as well as in peripheral organs, the precise mechanism(s) through which sleep buffers alcohol toxicity will undoubtedly be the focus of future studies.

Pharmacologically increasing sleep alone in circadianly disrupted and middle- aged wild-type flies was sufficient to significantly reduce alcohol-induced mortality. Gaboxadol increased total sleep duration as well as significantly increasing sleep bout length suggesting a greater consolidation of sleep. Both increased total sleep and increased sleep consolidation suggest that improved sleep quality could aid in mitigating alcohol-induced pathologies. Although there have been few studies examining the relationship between sleep health and alcohol toxicity, sleep loss or decreased sleep consolidation has been shown to reduce reproductive output, accelerate aging and increase the accumulation of reactive oxygen species and death in flies ${ }^{154,155}$. In humans, increasing sleep in adolescents is correlated with decreased risk of emotional and cognitive disruption as well as lowered risk of obesity ${ }^{156}$. Also, increasing sleep by 30 minutes for 3 days over the weekend in healthy industrial workers and individuals susceptible to obesity significantly increased insulin sensitivity and had a restorative effect of sleep on metabolic homeostasis ${ }^{157,158}$. Finally, increasing sleep in older adults significantly improves performance on visual tasks and stabilizes memory recall ${ }^{159}$. Although more specific research needs to be done assessing the direct effects of increased sleep on alcohol toxicity in vulnerable groups, these data suggest a role for sleep as a buffer to protect against the toxic effects of alcohol in populations vulnerable to chronic sleep loss as aged adults and shift workers.

The development of acute tolerance to alcohol is a distinct and critical behavioral metric used to gauge the propensity for alcohol dependence and abuse ${ }^{160}$, that can be separated from alcohol sensitivity and alcohol toxicity. Similar to mammals, an acute exposure to a high concentration of alcohol induces functional tolerance in Drosophila at the behavioral $1^{50,96,161}$ and the molecular levels ${ }^{97,162-165}$. Functional alcohol tolerance is dependent on changes in neuronal strength and connectivity or synaptic plasticity $^{97,162,163}$. Consistent with previous findings, we observed tolerance 4 hours and 24 hours 
following a short pre-exposure to alcohol vapor ${ }^{50,51}$. We found that sleep deprivation abolished the development of tolerance at 24 hours but had no effect on tolerance at 4 hours. Potentially, acute sleep deprivation selectively impairs the cellular and molecular processes necessary for encoding long-term rapid tolerance to alcohol without severe disruption of those mechanisms necessary for the development of 4 hour tolerance. In fact, previous studies demonstrate altered expression of rapid tolerance in flies with mutations in genes necessary for learning and memory ${ }^{46,96,166}$. For example, the gene dunce (dnc) encodes a phosophodiesterase required for cAMP degradation and is necessary for behavioral and synaptic plasticity ${ }^{167,168}$. Originally identified as a learning mutant ${ }^{169,170}, d n c$-mutant flies exhibit significant sleep deficits ${ }^{171}$ and are incapable of forming rapid tolerance ${ }^{172,173}$. Time-dependent differences in the effects of sleep deprivation can also be seen for memory with acute sleep deprivation affecting the consolidation of long-term but not short-term hippocampal dependent memory in mice ${ }^{174,175}$. Together with support from existing research, the results from our studies suggest that sleep deprivation selectively impacts processes underlying synaptic plasticity to affect the development of long-term rapid tolerance. In conclusion, the results from our study start to dissociate the role of sleep in modulating alcohol toxicity from the regulation of alcohol neurobiology by the circadian clock. These results lay the groundwork for future studies and treatments considering sleep quality and sleep duration as an important component of alcohol use disorder and alcohol-induced pathologies.

\section{Disclosure Statement}

Financial Disclosure: None

Non-financial Disclosure: None

An early version of this manuscript (the authors' original version) prior to peer review may be found in bioRxiv. 


\section{Figure Legends}

Figure 1: Acute sleep deprivation increases sensitivity to alcohol-induced sedation A) $10 \mathrm{~d}$ old WT CS flies were sleep - deprived for $24 \mathrm{~h}$ then exposed to $50 \%$ alcohol vapor for $1 \mathrm{~h}$. Sensitivity to sedation was measured by counting the number of flies sedated every 5 min. B) Sleep deprivation significantly exacerbates alcohol-induced sedation $\left(t_{(14)}=13.4558, p=0.0002\right)$. Mean time necessary for $50 \%$ of the flies to become sedated during alcohol exposure and standard error of the mean plotted for all experiments. C) Complete time course of alcohol exposure showing percent of flies exhibiting sedation for $10 \mathrm{~d}$ old sleep-deprived and non-sleep deprived flies. D) Separate groups of $10 \mathrm{~d}$ male and female flies were sleep deprived for $24 \mathrm{~h}$ then exposed to $50 \%$ alcohol vapor for $1 \mathrm{~h}$. Sleep-deprived males sedate faster compared to sleep-deprived females, indicating that increased sensitivity to alcohol sedation is not due to an exacerbated response to stress. (ANOVA $F_{3,28}=29.24, p<0.0001$ ). N shown on bars for each group is the number of vials tested for each group with 25-30 flies per vial. E) Complete time course of alcohol exposure showing percent of flies exhibiting sedation for $10 \mathrm{~d}$ old sleep-deprived and non-sleep deprived male and female flies.

Figure 2: Acute sleep deprivation exacerbates alcohol-induced mortality following a single and repeated exposures to alcohol. A) $10 \mathrm{~d}$ old WT CS flies were sleep - deprived for $24 \mathrm{~h}$ then exposed to $50 \%$ alcohol vapor for $1 \mathrm{~h}$. The number of flies that died were counted every $24 \mathrm{~h}$ for 7 days following alcohol exposure. B) Sleep-deprived flies exhibited a drastic increase in mortality within $24 \mathrm{~h}$ of exposure to alcohol compared to non-sleep deprived flies (ANOVA $F_{3,28}=22.50, p<0.0001$ ). C) Mortality continued to significantly rise 7 days following exposure to alcohol in both non-sleep deprived and sleep deprived flies (ANOVA: $F_{3,28}=14.01, p<0.0001$ ). D) $10 \mathrm{~d}$ old WT CS flies were sleep - deprived for 24 $\mathrm{h}$ followed by 3 consecutive exposures to $1 \mathrm{~h}$ alcohol (50\% alcohol vapor) at ZT 9 with each exposure separated by $24 \mathrm{~h}$. E) Sleep-deprived flies exhibited a drastic increase in mortality within $24 \mathrm{~h}$ of $1^{\text {st }}$ exposure to alcohol compared to non-sleep deprived flies (ANOVA: $F_{3,76}=15.42, p<0.0001$ ). F) Mortality continued to rise $24 \mathrm{~h}$ following the $3^{\text {rd }}$ exposure to alcohol vapor in both non-sleep deprived 
and sleep deprived flies (ANOVA: $F_{3,76}=14.42, p<0.0001$ ), although this rise was not significant. G) Mortality measured $7 \mathrm{~d}$ following the $3^{\text {rd }}$ alcohol exposure was significantly higher than mortality following the $1^{\text {st }}$ alcohol exposure (ANOVA: $F_{3,76}=19.91, p<0.0001$ ).

\section{Figure 3: Sleep deprivation does not affect alcohol accumulation or rate of alcohol clearance. A)}

Flies are aged in 12:12 LD cycle for 10 days then sleep deprived for $24 \mathrm{~h} .10 \mathrm{~d}$ CS flies are exposed to 30 min of $50 \%$ alcohol vapor on day 11 with alcohol absorbance and rate of alcohol clearance assessed. B) No significant differences exist in alcohol absorbance or rate of alcohol clearance between sleep deprived and non-sleep deprived flies ( $\mathrm{n}=4$ per group).

Figure 4: Mutations in insomniac do not increase behavioral sensitivity to alcohol exposure. The impact of sleep loss due to mutations in the $i n c^{l}$ and $i n c^{2}$ genes on alcohol sensitivity was assessed. A-C) Sleep profiles of $w^{1118}$, inc ${ }^{1}$ and $i n c^{2}$ flies. $i n c^{1}, i n c^{2}$ and flies have significantly shorter daily sleep times (A, ANOVA: $\left.F_{2,67}=81.13, p<0.0001\right)$, shorter bout lengths (B, ANOVA: $\left.F_{2,67}=17.52, p<0.0001\right)$ and increased number of bouts compared to $w^{1118}$ flies (C, ANOVA: $\left.F_{2,67}=8.64, p<0.0001\right)$. D) $10 \mathrm{~d} i n c^{l}$, $i n c^{2}$ and $w^{1118}$ control flies were exposed to $50 \%$ alcohol vapor for $1 \mathrm{~h}$ at ZT 9 with sedation assessed every 5 minutes during the alcohol exposure. E) $i n c^{l}$ and $i n c^{2}$ flies demonstrated increased resistance to alcohol vapor compared to $w^{1118}$ controls (ANOVA: $F_{2,34}=47.28, p<0.0001$ ). F) The complete time course for $w^{1118}, i n c^{1}$ and $i n c^{2}$ flies.

\section{Figure 5: Short sleeping flies have significantly increased mortality following a single exposure to}

alcohol. A) The impact of sleep loss due to mutations in $i n c^{l}$ and $i n c^{2}$ on alcohol-induced mortality was assessed. $10 \mathrm{~d} w^{1118}, i n c^{l}$ and $i n c^{2}$ flies were exposed to $50 \%$ alcohol vapor for $1 \mathrm{~h}$ at ZT 9 with mortality assessed every $24 \mathrm{~h}$ for $7 \mathrm{~d}$ following exposure to alcohol. B) $i n c^{1}$ and $i n c^{2}$ mutant flies showed significantly increased mortality $24 \mathrm{~h}$ following exposure to alcohol compared to $w^{1118}$ control flies (ANOVA: $F_{2,29}=16.46, p<0.0001$ ). C) Mortality in $i n c^{l}$ and $i n c^{2}$ flies continued to rise $7 \mathrm{~d}$ following the 
initial exposure to alcohol (ANOVA: $F_{2,29}=20.87, p<0.0001$ ). D) To determine whether the alcoholinduced mortality in $10 \mathrm{~d} i n c^{l}$ and $i n c^{2}$ flies was due to accumulation of sleep deficits, $3 \mathrm{~d} i n c^{l}$, inc $c^{2}$ and $w^{1118}$ control flies were exposed to $50 \%$ alcohol vapor for $1 \mathrm{~h}$ at ZT 9 with mortality assessed every $24 \mathrm{~h}$ for $7 \mathrm{~d}$ after alcohol exposure. E) The rate of mortality $24 \mathrm{~h}$ following exposure to alcohol was significantly higher in $3 \mathrm{~d} i n c^{l}$ and $i n c^{2}$ flies compared to $w^{1118}$ controls but significantly lower than that of $10 \mathrm{~d} i n c^{l}$ and $i n c^{2}$ flies (ANOVA: $F_{2,34}=15.03, p<0.0001$ ). F) Compared to $w^{1118}$ controls, the mortality in $i n c^{l}$ and $i n c^{2}$ mutant flies continued to rise $7 \mathrm{~d}$ following the alcohol exposure but remained lower than that of $10 \mathrm{~d} i n c^{l}$ and $i n c^{2}$ mutant flies (ANOVA: $F_{2,34}=25.01, p<0.0001$ ). These results support the hypothesis that sleep loss accumulated with age exacerbates susceptibility to alcohol-induced toxicity.

\section{Figure 6: Pharmacologically increasing sleep in insomniac mutants ameliorates mortality following}

alcohol exposure. A) To determine whether increased sleep buffered against the toxic effects of alcohol, $i n c^{1}, i n c^{2}$ and $w^{1118}$ flies were aged in LD cycles for $9 \mathrm{~d}$ and transferred to media containing $0.1 \mathrm{mg} / \mathrm{mL}$ THIP for $24 \mathrm{~h}$. On day 10, flies were exposed to $1 \mathrm{~h}$ of $50 \%$ alcohol vapor at ZT 9 with mortality being assessed every $24 \mathrm{~h}$ for $7 \mathrm{~d}$ following exposure. B) Significantly reduced mortality was observed in THIPfed $i n c^{l}$ and $i n c^{2}$ flies $24 \mathrm{~h}$ following alcohol exposure compared to $i n c^{l}$ and $i n c^{2}$ flies given alcohol alone (ANOVA: $F_{3,44}=13.27, p<0.0001$ ). C) Although mortality rose in THIP-fed $i n c^{l}$ and $i n c^{2}$ flies $7 \mathrm{~d}$ following alcohol exposure, the percent of THIP-fed $i n c^{l}$ and $i n c^{2}$ flies was still significantly lower than non-THIP fed $i n c^{l}$ and $i n c^{2}$ flies at $7 \mathrm{~d}$ after exposure to alcohol (ANOVA: $F_{2,44}=12.83, p<0.0001$ ). D) To determine whether the decreased mortality observed in THIP-fed flies was due to buildup of GABA-A receptor tolerance, $i n c^{1}, i n c^{2}$ and $w^{1118}$ flies were aged in LD cycles for $10 \mathrm{~d}$ and transferred to media containing $0.1 \mathrm{mg} / \mathrm{mL}$ THIP for $1 \mathrm{~h}$ at ZT 7 . At ZT 9, the flies were exposed to $1 \mathrm{~h}$ of $50 \%$ alcohol vapor with mortality being assessed every $24 \mathrm{~h}$ for $7 \mathrm{~d}$ following exposure. E) No significant differences in mortality were observed between THIP-fed $i n c^{l}$ and $i n c^{2}$ flies $24 \mathrm{~h}$ following alcohol exposure (ANOVA: $\left.F_{5,46}=50.88, p<0.0001\right)$. F) No significant differences in mortality were observed in THIP-fed $i n c^{l}$ and 
$i n c^{2}$ flies compared to non-THIP fed flies $7 \mathrm{~d}$ following alcohol exposure (ANOVA: $F_{5,46}=50.88, p<$ $0.0001)$.

Figure 7: Pharmacologically increasing sleep in flies that are circadianly disrupted reduces mortality following repeated exposures to alcohol. A-D) Comparison of sleep profiles between $10 \mathrm{~d}$ WT CS flies housed in LD cycles and $10 \mathrm{~d}$ flies housed in constant light conditions (LL). Compared to control WT flies grown in a 12:12 h LD cycle, $10 \mathrm{~d}$ WT CS flies grown in LL exhibit significantly decreased average sleep time per day $\left.\left(\mathrm{A},\left[t_{(236)}=4.46, p<0.0001\right)\right]\right)$, decreased sleep during both the light and dark cycle (B, ANOVA: $\left.F_{3,442}=27.31, p<0.0001\right)$, increased number of sleep bouts $(\mathrm{C}$, ANOVA: $\left.F_{3,442}=98.99, p<0.0001\right)$ and decreased bout duration (D, ANOVA: $\left.F_{3,442}=78.45, p<0.0001\right) .10 \mathrm{~d} \mathrm{LL}$ flies fed $0.1 \mathrm{mg} / \mathrm{mL}$ THIP exhibit significantly higher quiescence compared to $10 \mathrm{~d}$ LL flies on control media with significantly longer total sleep time per day $\left(\mathrm{E}, t_{(233)}=29.43, p<0.0001\right)$, increased sleep time during the light and dark cycles (F, ANOVA: $\left.F_{3,463}=437.1, p<0.0001\right)$, decreased number of sleep bouts $\left(\mathrm{G}\right.$, ANOVA: $\left.F_{3,463}=358.1, p<0.0001\right)$ and increased bout duration $\left(\mathrm{H}\right.$, ANOVA: $F_{3,463}=277.6, p<$ 0.0001). I) To determine whether increasing sleep was sufficient to ameliorate alcohol-induced mortality under conditions of circadian disruption, WT CS flies are housed in LL upon eclosion and transferred to media containing $0.1 \mathrm{mg} / \mathrm{mL}$ THIP on day 8 for $48 \mathrm{~h}$. On days 10,11 and 12 , flies were subjected to a three-exposure repeated binge-like alcohol paradigm with $1 \mathrm{~h}$ alcohol exposure (50\% alcohol vapor) occurring at ZT 9 and mortality was assessed. J) Alcohol-induced mortality in THIP-fed LL flies was drastically reduced compared to control LL flies (ANOVA: $F_{3,36}=132.6, p<0.0001$ ). K) Reduced mortality following THIP exposure is not due to increased tolerance as $1 \mathrm{~h}$ exposure to $0.1 \mathrm{mg} / \mathrm{mL}$ immediately prior to alcohol exposure had no significant effect on reducing alcohol-induced mortality (ANOVA: $\left.F_{3,36}=92.26, p<0.000\right)$.

Figure 8: Pharmacologically increasing sleep in aging ameliorates alcohol-induced mortality. Compared to young $10 \mathrm{~d}$ flies, $20 \mathrm{~d}$ flies grown in LD cycles exhibit significantly decreased average sleep 
time per day (A), decreased sleep during both the light and dark cycle (B), increased number of sleep bouts (C) and decreased bout duration (D). $20 \mathrm{~d}$ flies fed $0.1 \mathrm{mg} / \mathrm{mL}$ THIP exhibit significantly higher quiescence compared to $20 \mathrm{~d}$ flies on control media with significantly longer total sleep time per day (E) increased daytime and nighttime sleep. I) Flies are grown in $12 \mathrm{~h}$ light: $12 \mathrm{~h}$ dark cycles and transferred to media containing $0.1 \mathrm{mg} / \mathrm{mL}$ THIP on day 19 for $24 \mathrm{~h}$. On days 20, 21 and 22, flies were subjected to a 3exposure repeated binge-like alcohol paradigm with $1 \mathrm{~h}$ alcohol exposure (40\% alcohol vapor) occurring at ZT 9 and mortality was assessed. J) Increased quiescence in $20 \mathrm{~d}$ THIP-fed flies significantly ameliorated alcohol-induced mortality compared to $20 \mathrm{~d}$ flies fed control media (ANOVA $F_{3,44}=243.8, p$ $<0.0001)$. K) $20 \mathrm{~d}$ flies exposed for $1 \mathrm{~h}$ to $0.1 \mathrm{mg} / \mathrm{mL}$ THIP immediately prior to alcohol exposure had no significant effect on reducing alcohol-induced mortality $[t(9)=1.047, p=0.3223]$.

\section{Figure 9: Sleep deprivation differentially affects short-term and long-term functional tolerance. A-}

C) Effect of $24 \mathrm{~h}$ sleep deprivation on short-term functional alcohol tolerance. A) WT CS flies were aged in 12:12 h LD cycle and sleep deprived for $24 \mathrm{~h}$ on day 10 . On day 11 , flies were exposed to $50 \%$ alcohol vapor for $30 \mathrm{~min}$ and tested $4 \mathrm{~h}$ later by exposing to $50 \%$ alcohol vapor for $1 \mathrm{~h}$ with sedation being measured. B) $24 \mathrm{~h}$ sleep deprivation has no significant effect on the development of short-term acute alcohol tolerance. Both sleep deprived and non-sleep deprived flies exhibited alcohol tolerance (ANOVA $\left.F_{3,20}=49.62, p<0.0001\right)$. C) Complete time course of alcohol exposure showing percent of flies exhibiting sedation for $10 \mathrm{~d}$ old sleep-deprived and non-sleep deprived flies. D-F) Effect of sleep deprivation on development of long-term functional alcohol tolerance. WT CS flies were aged in 12:12 h LD cycle and sleep deprived for $24 \mathrm{~h}$ on day 10 . On day 11 , flies were exposed to $50 \%$ alcohol vapor for $30 \mathrm{~min}$ and tested $24 \mathrm{~h}$ later by exposing to $50 \%$ alcohol vapor for $1 \mathrm{~h}$ at ZT 9 with sedation being measured. E) Both sleep-deprived and non-sleep deprived flies exhibited alcohol tolerance (ANOVA $F_{3,26}$ $=125.7, p<0.0001$ ) with $24 \mathrm{~h}$ sleep deprivation significantly dampens development of long-term functional alcohol tolerance. F) Complete time course of alcohol exposure showing percent of flies exhibiting sedation for $10 \mathrm{~d}$ old sleep-deprived and non-sleep deprived flies. 


\section{References}

1. Esser MB, Hedden SL, Kanny D, Brewer RD, Gfroerer JC, Naimi TS. Prevalence of alcohol dependence among US adult drinkers, 2009-2011. Prev Chronic Dis. 2014; 11: E206.

2. Esser MB, Sherk A, Liu Y, et al. Deaths and Years of Potential Life Lost From Excessive Alcohol Use - United States, 2011-2015. MMWR Morb Mortal Wkly Rep. 2020; 69 (30): 981 987.

3. Grant BF, Dawson DA, Stinson FS, Chou SP, Dufour MC, Pickering RP. The 12-month prevalence and trends in DSM-IV alcohol abuse and dependence: United States, 1991-1992 and 2001-2002. Drug Alcohol Depend. 2004; 74 (3): 223-234.

4. Grant BF, Stinson FS, Dawson DA, Chou SP, Ruan WJ, Pickering RP. Co-occurrence of 12-month alcohol and drug use disorders and personality disorders in the United States: results from the National Epidemiologic Survey on Alcohol and Related Conditions. Arch Gen Psychiatry. 2004; 61 (4): 361-368.

5. Kesmodel U, Wisborg K, Olsen SF, Henriksen TB, Secher NJ. Moderate alcohol intake during pregnancy and the risk of stillbirth and death in the first year of life. Am J Epidemiol. 2002; 155 (4): 305-312.

6. Leonard KE, Rothbard JC. Alcohol and the marriage effect. J Stud Alcohol Suppl. 1999; 13: $139-146$.

7. Sacks JJ, Gonzales KR, Bouchery EE, Tomedi LE, Brewer RD. 2010 National and State Costs of Excessive Alcohol Consumption. Am J Prev Med. 2015; 49 (5): e73-e79.

8. Stahre M, Roeber J, Kanny D, Brewer RD, Zhang X. Contribution of excessive alcohol consumption to deaths and years of potential life lost in the United States. Prev Chronic Dis. 2014; 11: E109.

9. SAMSHA. Results from the 2013 National Survey on Drug Use and Health. Summary of national findings. NSDUH Series H-48. 2014; HHS Publication No. (SMA) 14-4863 (Substance Abuse and Mental Health Services Administration): Rockville, MD.

10. (HHS) UDoHaHS. Facing addiction in America: the surgeon general's report on alcohol, drugs, and health. In: General OotS, ed2016.

11. Blazer DG, Wu LT. The epidemiology of at-risk and binge drinking among middle-aged and elderly community adults: National Survey on Drug Use and Health. Am J Psychiatry. 2009; 166 (10): 1162-1169. 
12. Bushnell PT, Colombi A, Caruso CC, Tak S. Work schedules and health behavior outcomes at a large manufacturer. Ind Health. 2010; 48 (4): 395-405.

13. Hasler BP, Soehner AM, Clark DB. Sleep and circadian contributions to adolescent alcohol use disorder. Alcohol. 2015; 49 (4): 377-387.

14. Kendler KS, Ohlsson H, Sundquist J, Sundquist K. Alcohol Use Disorder and Mortality Across the Lifespan: A Longitudinal Cohort and Co-relative Analysis. JAMA Psychiatry. 2016. 15. Lee J, Manousakis J, Fielding J, Anderson C. Alcohol and sleep restriction combined reduces vigilant attention, whereas sleep restriction alone enhances distractibility. Sleep. 2015; 38 (5): 765-775.

16. Novier A, Diaz-Granados JL, Matthews DB. Alcohol use across the lifespan: An analysis of adolescent and aged rodents and humans. Pharmacol Biochem Behav. 2015; 133: 65-82.

17. Novier A, Ornelas LC, Diaz-Granados JL, Matthews DB. Differences in Behavioral Responding in Adult and Aged Rats Following Chronic Ethanol Exposure. Alcohol Clin Exp Res. 2016; 40 (7): 1462-1472.

18. Swanson GR, Gorenz A, Shaikh M, et al. Night workers with circadian misalignment are susceptible to alcohol-induced intestinal hyperpermeability with social drinking. Am J Physiol Gastrointest Liver Physiol. 2016; 311 (1): G192-201.

19. Chakravorty S, Chaudhary NS, Brower KJ. Alcohol Dependence and Its Relationship With Insomnia and Other Sleep Disorders. Alcohol Clin Exp Res. 2016.

20. Colrain IM, Nicholas CL, Baker FC. Alcohol and the sleeping brain. Handb Clin Neurol. 2014; 125: 415-431.

21. Ebrahim IO, Shapiro CM, Williams AJ, Fenwick PB. Alcohol and sleep I: effects on normal sleep. Alcohol Clin Exp Res. 2013; 37 (4): 539-549.

22. Brower KJ, Aldrich MS, Hall JM. Polysomnographic and subjective sleep predictors of alcoholic relapse. Alcohol Clin Exp Res. 1998; 22 (8): 1864-1871.

23. Brower KJ, Hall JM. Effects of age and alcoholism on sleep: a controlled study. J Stud Alcohol. 2001; 62 (3): 335-343.

24. Hartwell EE, Bujarski S, Glasner-Edwards S, Ray LA. The Association of Alcohol Severity and Sleep Quality in Problem Drinkers. Alcohol Alcohol. 2015; 50 (5): 536-541. 
25. Smith N, Hill R, Marshall J, Keaney F, Wanigaratne S. Sleep related beliefs and their association with alcohol relapse following residential alcohol detoxification treatment. Behav Cogn Psychother. 2014; 42 (5): 593-604.

26. Buxton OM, Marcelli E. Short and long sleep are positively associated with obesity, diabetes, hypertension, and cardiovascular disease among adults in the United States. Soc Sci Med. 2010; 71 (5): 1027-1036.

27. Garbarino S, Lanteri P, Durando P, Magnavita N, Sannita WG. Co-Morbidity, Mortality, Quality of Life and the Healthcare/Welfare/Social Costs of Disordered Sleep: A Rapid Review. Int J Environ Res Public Health. 2016; 13 (8).

28. Strine TW, Chapman DP. Associations of frequent sleep insufficiency with health-related quality of life and health behaviors. Sleep Med. 2005; 6 (1): 23-27.

29. Wheaton AG, Olsen EO, Miller GF, Croft JB. Sleep Duration and Injury-Related Risk Behaviors Among High School Students--United States, 2007-2013. MMWR Morb Mortal Wkly Rep. 2016; 65 (13): 337-341.

30. Knutson KL, Van Cauter E, Rathouz PJ, DeLeire T, Lauderdale DS. Trends in the prevalence of short sleepers in the USA: 1975-2006. Sleep. 2010; 33 (1): 37-45.

31. Roenneberg T. Chronobiology: the human sleep project. Nature. 2013; 498 (7455): 427428.

32. Landayan D, Wolf FW. Shared neurocircuitry underlying feeding and drugs of abuse in Drosophila. Biomed J. 2015; 38 (6): 496-509.

33. Park A, Ghezzi A, Wijesekera TP, Atkinson NS. Genetics and genomics of alcohol responses in drosophila. Neuropharmacology. 2017.

34. Tomita J, Ban G, Kume K. Genes and neural circuits for sleep of the fruit fly. Neurosci Res. 2017.

35. Andretic R, Shaw PJ. Essentials of sleep recordings in Drosophila: moving beyond sleep time. Methods Enzymol. 2005; 393: 759-772.

36. Donlea JM. Neuronal and molecular mechanisms of sleep homeostasis. Curr Opin Insect Sci. 2017; 24: 51-57.

37. Hendricks JC, Finn SM, Panckeri KA, et al. Rest in Drosophila is a sleep-like state.

Neuron. 2000; 25 (1): 129-138. 
38. Huber R, Hill SL, Holladay C, Biesiadecki M, Tononi G, Cirelli C. Sleep homeostasis in Drosophila melanogaster. Sleep. 2004; 27 (4): 628-639.

39. Isaac RE, Li C, Leedale AE, Shirras AD. Drosophila male sex peptide inhibits siesta sleep and promotes locomotor activity in the post-mated female. Proc Biol Sci. 2010; 277 (1678): 65-70.

40. Koh K, Evans JM, Hendricks JC, Sehgal A. A Drosophila model for age-associated changes in sleep:wake cycles. Proc Natl Acad Sci U S A. 2006; 103 (37): 13843-13847.

41. Robertson M, Keene AC. Molecular mechanisms of age-related sleep loss in the fruit fly - a mini-review. Gerontology. 2013; 59 (4): 334-339.

42. Shaw PJ, Cirelli C, Greenspan RJ, Tononi G. Correlates of sleep and waking in Drosophila melanogaster. Science. 2000; 287 (5459): 1834-1837.

43. van Alphen B, Yap MH, Kirszenblat L, Kottler B, van Swinderen B. A dynamic deep sleep stage in Drosophila. J Neurosci. 2013; 33 (16): 6917-6927.

44. Vienne J, Spann R, Guo F, Rosbash M. Age-Related Reduction of Recovery Sleep and Arousal Threshold in Drosophila. Sleep. 2016; 39 (8): 1613-1624.

45. Ganguly-Fitzgerald I, Donlea J, Shaw PJ. Waking experience affects sleep need in Drosophila. Science. 2006; 313 (5794): 1775-1781.

46. Devineni AV, McClure KD, Guarnieri DJ, et al. The genetic relationships between ethanol preference, acute ethanol sensitivity, and ethanol tolerance in Drosophila melanogaster. Fly (Austin). 2011; 5 (3): 191-199.

47. Rodan AR, Rothenfluh A. The genetics of behavioral alcohol responses in Drosophila. Int Rev Neurobiol. 2010; 91: 25-51.

48. De Nobrega AK, Lyons LC. Circadian Modulation of Alcohol-Induced Sedation and Recovery in Male and Female Drosophila. J Biol Rhythms. 2016.

49. Moore MS, DeZazzo J, Luk AY, Tully T, Singh CM, Heberlein U. Ethanol intoxication in Drosophila: Genetic and pharmacological evidence for regulation by the cAMP signaling pathway. Cell. 1998; 93 (6): 997-1007.

50. Scholz H, Ramond J, Singh CM, Heberlein U. Functional ethanol tolerance in Drosophila. Neuron. 2000; 28 (1): 261-271.

51. van der Linde K, Lyons LC. Circadian modulation of acute alcohol sensitivity but not acute tolerance in Drosophila. Chronobiol Int. 2011; 28 (5): 397-406. 
52. Cowmeadow RB, Krishnan HR, Atkinson NS. The slowpoke gene is necessary for rapid ethanol tolerance in Drosophila. Alcohol Clin Exp Res. 2005; 29 (10): 1777-1786.

53. Ghezzi A, Al-Hasan YM, Krishnan HR, Wang Y, Atkinson NS. Functional mapping of the neuronal substrates for drug tolerance in Drosophila. Behav Genet. 2013; 43 (3): 227-240.

54. Ghezzi A, Li X, Lew LK, Wijesekera TP, Atkinson NS. Alcohol-Induced Neuroadaptation Is Orchestrated by the Histone Acetyltransferase CBP. Front Mol Neurosci. 2017; 10: 103.

55. Krishnan HR, Li X, Ghezzi A, Atkinson NS. A DNA element in the slo gene modulates ethanol tolerance. Alcohol. 2016; 51:37-42.

56. Devineni AV, Heberlein U. Preferential ethanol consumption in Drosophila models features of addiction. Curr Biol. 2009; 19 (24): 2126-2132.

57. Kaun KR, Azanchi R, Maung Z, Hirsh J, Heberlein U. A Drosophila model for alcohol reward. Nat Neurosci. 2011; 14 (5): 612-619.

58. Kaun KR, Devineni AV, Heberlein U. Drosophila melanogaster as a model to study drug addiction. Hum Genet. 2012; 131 (6): 959-975.

59. Xu S, Chan T, Shah V, Zhang S, Pletcher SD, Roman G. The propensity for consuming ethanol in Drosophila requires rutabaga adenylyl cyclase expression within mushroom body neurons. Genes Brain Behav. 2012; 11 (6): 727-739.

60. Peru Y Colón de Portugal RL, Ojelade SA, Penninti PS, et al. Long-lasting, experiencedependent alcohol preference in Drosophila. Addict Biol. 2014; 19 (3): 392-401.

61. De Nobrega AK, Mellers AP, Lyons LC. Aging and circadian dysfunction increase alcohol sensitivity and exacerbate mortality in Drosophila melanogaster. Exp Gerontol. 2017; 97: 49-59.

62. van der Linde K, Fumagalli E, Roman G, Lyons LC. The FlyBar: administering alcohol to flies. J Vis Exp. 2014; (87).

63. Lyons LC, Roman G. Circadian modulation of short-term memory in Drosophila. Learn Mem. 2009; 16 (1): 19-27.

64. Dorrian J, Heath G, Sargent C, Banks S, Coates A. Alcohol use in shiftworkers. Accid Anal Prev. 2017; 99 (Pt B): 395-400.

65. Dorrian J, Skinner N. Alcohol consumption patterns of shiftworkers compared with dayworkers. Chronobiol Int. 2012; 29 (5): 610-618. 
66. Kenney SR, LaBrie JW, Hummer JF, Pham AT. Global sleep quality as a moderator of alcohol consumption and consequences in college students. Addict Behav. 2012; 37 (4): 507512.

67. Morikawa Y, Sakurai M, Nakamura K, et al. Correlation between shift-work-related sleep problems and heavy drinking in Japanese male factory workers. Alcohol Alcohol. 2013; 48 (2): 202-206.

68. Wong MM, Brower KJ, Nigg JT, Zucker RA. Childhood sleep problems, response inhibition, and alcohol and drug outcomes in adolescence and young adulthood. Alcohol Clin Exp Res. 2010; 34 (6): 1033-1044.

69. Wong MM, Robertson GC, Dyson RB. Prospective relationship between poor sleep and substance-related problems in a national sample of adolescents. Alcohol Clin Exp Res. 2015; 39 (2): 355-362.

70. Helfrich-Förster C. Differential control of morning and evening components in the activity rhythm of Drosophila melanogaster--sex-specific differences suggest a different quality of activity. J Biol Rhythms. 2000; 15 (2): 135-154.

71. Kanny D, Brewer RD, Mesnick JB, Paulozzi LJ, Naimi TS, Lu H. Vital signs: alcohol poisoning deaths - United States, 2010-2012. MMWR Morb Mortal Wkly Rep. 2015; 63 (53): 1238-1242.

72. White AM, Slater ME, Ng G, Hingson R, Breslow R. Trends in Alcohol-Related Emergency Department Visits in the United States: Results from the Nationwide Emergency Department Sample, 2006 to 2014. Alcohol Clin Exp Res. 2018; 42 (2): 352-359.

73. Pasch KE, Latimer LA, Cance JD, Moe SG, Lytle LA. Longitudinal bi-directional relationships between sleep and youth substance use. J Youth Adolesc. 2012; 41 (9): 1184-1196.

74. Watson NF, Badr MS, Belenky G, et al. Recommended Amount of Sleep for a Healthy Adult: A Joint Consensus Statement of the American Academy of Sleep Medicine and Sleep Research Society. J Clin Sleep Med. 2015; 11 (6): 591-592.

75. Wheaton AG, Chapman DP, Croft JB. School Start Times, Sleep, Behavioral, Health, and Academic Outcomes: A Review of the Literature. J Sch Health. 2016; 86 (5): 363-381.

76. Stavropoulos N, Young MW. insomniac and Cullin-3 regulate sleep and wakefulness in Drosophila. Neuron. 2011; 72 (6): 964-976. 
77. Dissel S, Angadi V, Kirszenblat L, et al. Sleep restores behavioral plasticity to Drosophila mutants. Curr Biol. 2015; 25 (10): 1270-1281.

78. Berry JA, Cervantes-Sandoval I, Chakraborty M, Davis RL. Sleep Facilitates Memory by Blocking Dopamine Neuron-Mediated Forgetting. Cell. 2015; 161 (7): 1656-1667.

79. Tainton-Heap LAL, Kirszenblat LC, Notaras ET, et al. A Paradoxical Kind of Sleep in Drosophila melanogaster. Curr Biol. 2021; 31 (3): 578-590.e576.

80. Vashchinkina E, Panhelainen A, Vekovischeva OY, et al. GABA site agonist gaboxadol induces addiction-predicting persistent changes in ventral tegmental area dopamine neurons but is not rewarding in mice or baboons. J Neurosci. 2012; 32 (15): 5310-5320.

81. Ewer J, Frisch B, Hamblen-Coyle MJ, Rosbash M, Hall JC. Expression of the period clock gene within different cell types in the brain of Drosophila adults and mosaic analysis of these cells' influence on circadian behavioral rhythms. J Neurosci. 1992; 12 (9): 3321-3349. 82. Konopka RJ, Pittendrigh C, Orr D. Reciprocal behaviour associated with altered homeostasis and photosensitivity of Drosophila clock mutants. J Neurogenet. 1989; 6 (1): 1-10. 83. Price JL, Dembinska ME, Young MW, Rosbash M. Suppression of PERIOD protein abundance and circadian cycling by the Drosophila clock mutation timeless. EMBO J. 1995; 14 (16): 4044-4049.

84. Yoshii T, Heshiki Y, Ibuki-Ishibashi T, Matsumoto A, Tanimura T, Tomioka K. Temperature cycles drive Drosophila circadian oscillation in constant light that otherwise induces behavioural arrhythmicity. Eur J Neurosci. 2005; 22 (5): 1176-1184.

85. Power J, Ringo J, Dowse H. The role of light in the initiation of circadian activity rhythms of adult Drosophila melanogaster. J Neurogenet. 1995; 9 (4): 227-238.

86. Arellanes-Licea E, Caldelas I, De Ita-Pérez D, Díaz-Muñoz M. The circadian timing system: a recent addition in the physiological mechanisms underlying pathological and aging processes. Aging Dis. 2014; 5 (6): 406-418.

87. Bah TM, Goodman J, Iliff JJ. Sleep as a Therapeutic Target in the Aging Brain. Neurotherapeutics. 2019; 16 (3): 554-568.

88. Mander BA, Winer JR, Walker MP. Sleep and Human Aging. Neuron. 2017; 94 (1): 1936. 
89. Tevy MF, Giebultowicz J, Pincus Z, Mazzoccoli G, Vinciguerra M. Aging signaling pathways and circadian clock-dependent metabolic derangements. Trends Endocrinol Metab. 2013; 24 (5): 229-237.

90. Zhong HH, Yu B, Luo D, et al. Roles of aging in sleep. Neurosci Biobehav Rev. 2019; 98: 177-184.

91. Han BH, Moore AA, Ferris R, Palamar JJ. Binge Drinking Among Older Adults in the United States, 2015 to 2017. J Am Geriatr Soc. 2019; 67 (10): 2139-2144.

92. Han BH, Moore AA, Sherman SE, Palamar JJ. Prevalence and correlates of binge drinking among older adults with multimorbidity. Drug Alcohol Depend. 2018; 187: 48-54.

93. Wan H, Goodkind, D and Kowal, P. An Aging World: 2015. US Census Bureau, International Population Reports. 2015; P95 (16-1).

94. Abrahao KP, Salinas AG, Lovinger DM. Alcohol and the Brain: Neuronal Molecular Targets, Synapses, and Circuits. Neuron. 2017; 96 (6): 1223-1238.

95. Roberto M, Varodayan FP. Synaptic targets: Chronic alcohol actions.

Neuropharmacology. 2017.

96. Berger KH, Heberlein U, Moore MS. Rapid and chronic: two distinct forms of ethanol tolerance in Drosophila. Alcohol Clin Exp Res. 2004; 28 (10): 1469-1480.

97. Cowmeadow RB, Krishnan HR, Ghezzi A, Al'Hasan YM, Wang YZ, Atkinson NS. Ethanol tolerance caused by slowpoke induction in Drosophila. Alcohol Clin Exp Res. 2006; 30 (5): 745-753.

98. Engel GL, Taber K, Vinton E, Crocker AJ. Studying alcohol use disorder using Drosophila melanogaster in the era of 'Big Data'. Behav Brain Funct. 2019; 15 (1): 7.

99. Heyne A, May T, Goll P, Wolffgramm J. Persisting consequences of drug intake: towards a memory of addiction. J Neural Transm (Vienna). 2000; 107 (6): 613-638.

100. Van Skike CE, Goodlett C, Matthews DB. Acute alcohol and cognition: Remembering what it causes us to forget. Alcohol. 2019; 79: 105-125.

101. Havekes R, Park AJ, Tudor JC, et al. Sleep deprivation causes memory deficits by negatively impacting neuronal connectivity in hippocampal area CA1. Elife. 2016; 5.

102. Krishnan HC, Gandour CE, Ramos JL, Wrinkle MC, Sanchez-Pacheco JJ, Lyons LC. Acute Sleep Deprivation Blocks Short- and Long-Term Operant Memory in. Sleep. 2016; 39 (12): 2161-2171. 
103. Saygin M, Ozguner MF, Onder O, Doguc DK, Ilhan I, Peker Y. The impact of sleep deprivation on hippocampal-mediated learning and memory in rats. Bratisl Lek Listy. 2017; 118 (7): 408-416.

104. Bishehsari F, Saadalla A, Khazaie K, et al. Light/Dark Shifting Promotes AlcoholInduced Colon Carcinogenesis: Possible Role of Intestinal Inflammatory Milieu and Microbiota. Int J Mol Sci. 2016; 17 (12).

105. Voigt RM, Forsyth CB, Shaikh M, et al. Diurnal variations in intestinal barrier integrity and liver pathology in mice: implications for alcohol binge. Am J Physiol Gastrointest Liver Physiol. 2018; 314 (1): G131-G141.

106. Reid KJ, Abbott SM. Jet Lag and Shift Work Disorder. Sleep Med Clin. 2015; 10 (4): 523-535.

107. Haynie DL, Lewin D, Luk JW, et al. Beyond Sleep Duration: Bidirectional Associations Among Chronotype, Social Jetlag, and Drinking Behaviors in a Longitudinal Sample of US High School Students. Sleep. 2018; 41 (2).

108. Hasler BP, Wallace ML, White SJ, Molina BSG, Pedersen SL. Preliminary Evidence That Real World Sleep Timing and Duration are Associated With Laboratory-Assessed Alcohol Response. Alcohol Clin Exp Res. 2019; 43 (7): 1575-1584.

109. O'Brien EM, Mindell JA. Sleep and risk-taking behavior in adolescents. Behav Sleep Med. 2005; 3 (3): 113-133.

110. Schweizer CA, Hoggatt KJ, Washington DL, et al. Use of alcohol as a sleep aid, unhealthy drinking behaviors, and sleeping pill use among women veterans. Sleep Health. 2019; 5 (5): 495-500.

111. Dorrian J, Baulk SD, Dawson D. Work hours, workload, sleep and fatigue in Australian Rail Industry employees. Appl Ergon. 2011; 42 (2): 202-209.

112. Buchvold HV, Pallesen S, Øyane NM, Bjorvatn B. Associations between night work and BMI, alcohol, smoking, caffeine and exercise--a cross-sectional study. BMC Public Health. 2015; 15: 1112.

113. Giannotti F, Cortesi F, Sebastiani T, Ottaviano S. Circadian preference, sleep and daytime behaviour in adolescence. J Sleep Res. 2002; 11 (3): 191-199.

114. Pieters S, Van Der Vorst H, Burk WJ, Wiers RW, Engels RC. Puberty-dependent sleep regulation and alcohol use in early adolescents. Alcohol Clin Exp Res. 2010; 34 (9): 1512-1518. 
115. Pieters S, van der Vorst H, Engels RC, Wiers RW. Implicit and explicit cognitions related to alcohol use in children. Addict Behav. 2010; 35 (5): 471-478.

116. Robinson D, Gelaye B, Tadesse MG, Williams MA, Lemma S, Berhane Y. Daytime Sleepiness, Circadian Preference, Caffeine Consumption and Khat Use among College Students in Ethiopia. J Sleep Disord Treat Care. 2013; 3 (1).

117. Saxvig IW, Pallesen S, Wilhelmsen-Langeland A, Molde H, Bjorvatn B. Prevalence and correlates of delayed sleep phase in high school students. Sleep Med. 2012; 13 (2): 193-199.

118. Tavernier R, Willoughby T. Bidirectional associations between sleep (quality and duration) and psychosocial functioning across the university years. Dev Psychol. 2014; 50 (3): 674-682.

119. Urbán R, Magyaródi T, Rigó A. Morningness-eveningness, chronotypes and healthimpairing behaviors in adolescents. Chronobiol Int. 2011; 28 (3): 238-247.

120. Díaz-Morales JF, Escribano C, Jankowski KS. Chronotype and time-of-day effects on mood during school day. Chronobiol Int. 2015; 32 (1): 37-42.

121. Gruber R, Michaelsen S, Bergmame L, et al. Short sleep duration is associated with teacher-reported inattention and cognitive problems in healthy school-aged children. Nat Sci Sleep. 2012; 4: 33-40.

122. Hasler BP, Sitnick SL, Shaw DS, Forbes EE. An altered neural response to reward may contribute to alcohol problems among late adolescents with an evening chronotype. Psychiatry Res. 2013; 214 (3): 357-364.

123. Sadeh A, Gruber R, Raviv A. The effects of sleep restriction and extension on school-age children: what a difference an hour makes. Child Dev. 2003; 74 (2): 444-455.

124. Short MA, Gradisar M, Lack LC, Wright HR. The impact of sleep on adolescent depressed mood, alertness and academic performance. J Adolesc. 2013; 36 (6): 1025-1033. 125. Digdon N, Landry K. University students' motives for drinking alcohol are related to evening preference, poor sleep, and ways of coping with stress. Biological Rhythm Research. 2013; 44 (1): 1-11.

126. Rique GL, Fernandes Filho GM, Ferreira AD, de Sousa-Muñoz RL. Relationship between chronotype and quality of sleep in medical students at the Federal University of Paraiba, Brazil. Sleep Sci. 2014; 7 (2): 96-102. 
127. Martin JS, Hébert M, Ledoux E, Gaudreault M, Laberge L. Relationship of chronotype to sleep, light exposure, and work-related fatigue in student workers. Chronobiol Int. 2012; 29 (3): 295-304.

128. Bixler EO, Vgontzas AN, Lin HM, et al. Sleep disordered breathing in children in a general population sample: prevalence and risk factors. Sleep. 2009; 32 (6): 731-736.

129. Owens J, Group ASW, Adolescence Co. Insufficient sleep in adolescents and young adults: an update on causes and consequences. Pediatrics. 2014; 134 (3): e921-932.

130. Paruthi S, Brooks LJ, D'Ambrosio C, et al. Recommended Amount of Sleep for Pediatric Populations: A Consensus Statement of the American Academy of Sleep Medicine. J Clin Sleep Med. 2016; 12 (6): 785-786.

131. Wheaton AG, Ferro GA, Croft JB. School Start Times for Middle School and High School Students - United States, 2011-12 School Year. MMWR Morb Mortal Wkly Rep. 2015; 64 (30): 809-813.

132. Knutson KL, Van Cauter E. Associations between sleep loss and increased risk of obesity and diabetes. Ann N Y Acad Sci. 2008; 1129: 287-304.

133. Stone CR, Haig TR, Fiest KM, McNeil J, Brenner DR, Friedenreich CM. The association between sleep duration and cancer-specific mortality: a systematic review and meta-analysis. Cancer Causes Control. 2019; 30 (5): 501-525.

134. Van Egroo M, Narbutas J, Chylinski D, et al. Sleep-wake regulation and the hallmarks of the pathogenesis of Alzheimer's disease. Sleep. 2019; 42 (4).

135. Videnovic A, Lazar AS, Barker RA, Overeem S. 'The clocks that time us'--circadian rhythms in neurodegenerative disorders. Nat Rev Neurol. 2014; 10 (12): 683-693.

136. Videnovic A, Noble C, Reid KJ, et al. Circadian melatonin rhythm and excessive daytime sleepiness in Parkinson disease. JAMA Neurol. 2014; 71 (4): 463-469.

137. Clark CP, Gillin JC, Golshan S, et al. Increased REM sleep density at admission predicts relapse by three months in primary alcoholics with a lifetime diagnosis of secondary depression. Biol Psychiatry. 1998; 43 (8): 601-607.

138. García-García F, Priego-Fernández S, López-Muciño LA, Acosta-Hernández ME, PeñaEscudero C. Increased alcohol consumption in sleep-restricted rats is mediated by delta FosB induction. Alcohol. 2021. 
139. He S, Hasler BP, Chakravorty S. Alcohol and sleep-related problems. Curr Opin Psychol. 2019; 30: 117-122.

140. Roehrs T, Papineau K, Rosenthal L, Roth T. Ethanol as a hypnotic in insomniacs: self administration and effects on sleep and mood. Neuropsychopharmacology. 1999; 20 (3): 279286.

141. Araujo NP, Andersen ML, Abílio VC, et al. Sleep deprivation abolishes the locomotor stimulant effect of ethanol in mice. Brain Res Bull. 2006; 69 (3): 332-337.

142. McKnight-Eily LR, Eaton DK, Lowry R, Croft JB, Presley-Cantrell L, Perry GS. Relationships between hours of sleep and health-risk behaviors in US adolescent students. Prev Med. 2011; 53 (4-5): 271-273.

143. Sivertsen B, Skogen JC, Jakobsen R, Hysing M. Sleep and use of alcohol and drug in adolescence. A large population-based study of Norwegian adolescents aged 16 to 19 years. Drug Alcohol Depend. 2015; 149: 180-186.

144. Tynjälä J, Kannas L, Levälahti E. Perceived tiredness among adolescents and its association with sleep habits and use of psychoactive substances. J Sleep Res. 1997; 6 (3): 189198.

145. Du C, Zan MCH, Cho MJ, et al. The Effects of Sleep Quality and Resilience on Perceived Stress, Dietary Behaviors, and Alcohol Misuse: A Mediation-Moderation Analysis of Higher Education Students from Asia, Europe, and North America during the COVID-19 Pandemic. Nutrients. 2021; 13 (2).

146. Kenney SR, Lac A, Labrie JW, Hummer JF, Pham A. Mental health, sleep quality, drinking motives, and alcohol-related consequences: a path-analytic model. J Stud Alcohol Drugs. 2013; 74 (6): 841-851.

147. Hasler BP, Bootzin RR, Cousins JC, Fridel K, Wenk GL. Circadian phase in sleepdisturbed adolescents with a history of substance abuse: a pilot study. Behav Sleep Med. 2008; 6 (1): 55-73.

148. Hasler BP, Kirisci L, Clark DB. Restless Sleep and Variable Sleep Timing During Late Childhood Accelerate the Onset of Alcohol and Other Drug Involvement. J Stud Alcohol Drugs. 2016; 77 (4): 649-655. 
149. Hasler BP, Martin CS, Wood DS, Rosario B, Clark DB. A longitudinal study of insomnia and other sleep complaints in adolescents with and without alcohol use disorders. Alcohol Clin Exp Res. 2014; 38 (8): 2225-2233.

150. Mike TB, Shaw DS, Forbes EE, Sitnick SL, Hasler BP. The hazards of bad sleep-Sleep duration and quality as predictors of adolescent alcohol and cannabis use. Drug Alcohol Depend. 2016; 168: 335-339.

151. Wong MM, Brower KJ, Fitzgerald HE, Zucker RA. Sleep problems in early childhood and early onset of alcohol and other drug use in adolescence. Alcohol Clin Exp Res. 2004; 28 (4): 578-587.

152. Johnson EO, Breslau N. Sleep problems and substance use in adolescence. Drug Alcohol Depend. 2001; 64 (1): 1-7.

153. Hill VM, O'Connor RM, Sissoko GB, et al. A bidirectional relationship between sleep and oxidative stress in Drosophila. PLoS Biol. 2018; 16 (7): e2005206.

154. Vaccaro A, Kaplan Dor Y, Nambara K, et al. Sleep Loss Can Cause Death through Accumulation of Reactive Oxygen Species in the Gut. Cell. 2020; 181 (6): 1307-1328.e1315. 155. Potdar S, Daniel DK, Thomas FA, Lall S, Sheeba V. Sleep deprivation negatively impacts reproductive output in. J Exp Biol. 2018; 221 (Pt 6).

156. Dong L, Martinez AJ, Buysse DJ, Harvey AG. A composite measure of sleep health predicts concurrent mental and physical health outcomes in adolescents prone to eveningness. Sleep Health. 2019; 5 (2): 166-174.

157. Killick R, Hoyos CM, Melehan KL, Dungan GC, Poh J, Liu PY. Metabolic and hormonal effects of 'catch-up' sleep in men with chronic, repetitive, lifestyle-driven sleep restriction. Clin Endocrinol (Oxf). 2015; 83 (4): 498-507.

158. Leproult R, Deliens G, Gilson M, Peigneux P. Beneficial impact of sleep extension on fasting insulin sensitivity in adults with habitual sleep restriction. Sleep. 2015; 38 (5): 707-715. 159. Sonni A, Spencer RMC. Sleep protects memories from interference in older adults. Neurobiol Aging. 2015; 36 (7): 2272-2281.

160. Fillmore MT, Weafer J. Acute tolerance to alcohol in at-risk binge drinkers. Psychol Addict Behav. 2012; 26 (4): 693-702. 
161. Kong EC, Allouche L, Chapot PA, et al. Ethanol-regulated genes that contribute to ethanol sensitivity and rapid tolerance in Drosophila. Alcohol Clin Exp Res. 2010; 34 (2): 302316.

162. Lasek AW, Giorgetti F, Berger KH, Tayor S, Heberlein U. Lmo genes regulate behavioral responses to ethanol in Drosophila melanogaster and the mouse. Alcohol Clin Exp Res. 2011; 35 (9): 1600-1606.

163. Lasek AW, Lim J, Kliethermes CL, et al. An evolutionary conserved role for anaplastic lymphoma kinase in behavioral responses to ethanol. PLoS One. 2011; 6 (7): e22636.

164. Pietrzykowski AZ, Friesen RM, Martin GE, et al. Posttranscriptional regulation of BK channel splice variant stability by miR-9 underlies neuroadaptation to alcohol. Neuron. 2008; 59 (2): $274-287$.

165. Savarese A, Zou ME, Kharazia V, Maiya R, Lasek AW. Increased behavioral responses to ethanol in Lmo3 knockout mice. Genes Brain Behav. 2014; 13 (8): 777-783.

166. LaFerriere H, Guarnieri DJ, Sitaraman D, Diegelmann S, Heberlein U, Zars T. Genetic dissociation of ethanol sensitivity and memory formation in Drosophila melanogaster. Genetics. 2008; 178 (4): 1895-1902.

167. Chen CN, Denome S, Davis RL. Molecular analysis of cDNA clones and the corresponding genomic coding sequences of the Drosophila dunce+ gene, the structural gene for cAMP phosphodiesterase. Proc Natl Acad Sci U S A. 1986; 83 (24): 9313-9317.

168. Qiu YH, Chen CN, Malone T, Richter L, Beckendorf SK, Davis RL. Characterization of the memory gene dunce of Drosophila melanogaster. J Mol Biol. 1991; 222 (3): 553-565.

169. Dudai Y, Jan YN, Byers D, Quinn WG, Benzer S. dunce, a mutant of Drosophila deficient in learning. Proc Natl Acad Sci U S A. 1976; 73 (5): 1684-1688.

170. Nighorn A, Healy MJ, Davis RL. The cyclic AMP phosphodiesterase encoded by the Drosophila dunce gene is concentrated in the mushroom body neuropil. Neuron. 1991; 6 (3): 455-467.

171. Kirszenblat L, Ertekin D, Goodsell J, Zhou Y, Shaw PJ, van Swinderen B. Sleep regulates visual selective attention in. J Exp Biol. 2018; 221 (Pt 24).

172. Ruppert M, Franz M, Saratsis A, et al. Hangover Links Nuclear RNA Signaling to cAMP Regulation via the Phosphodiesterase 4d Ortholog dunce. Cell Rep. 2017; 18 (2): 533-544. 
173. Scholz H, Franz M, Heberlein U. The hangover gene defines a stress pathway required for ethanol tolerance development. Nature. 2005; 436 (7052): 845-847.

174. Graves LA, Heller EA, Pack AI, Abel T. Sleep deprivation selectively impairs memory consolidation for contextual fear conditioning. Learn Mem. 2003; 10 (3): 168-176.

175. Prince TM, Wimmer M, Choi J, Havekes R, Aton S, Abel T. Sleep deprivation during a specific 3-hour time window post-training impairs hippocampal synaptic plasticity and memory. Neurobiol Learn Mem. 2014; 109: 122-130. 

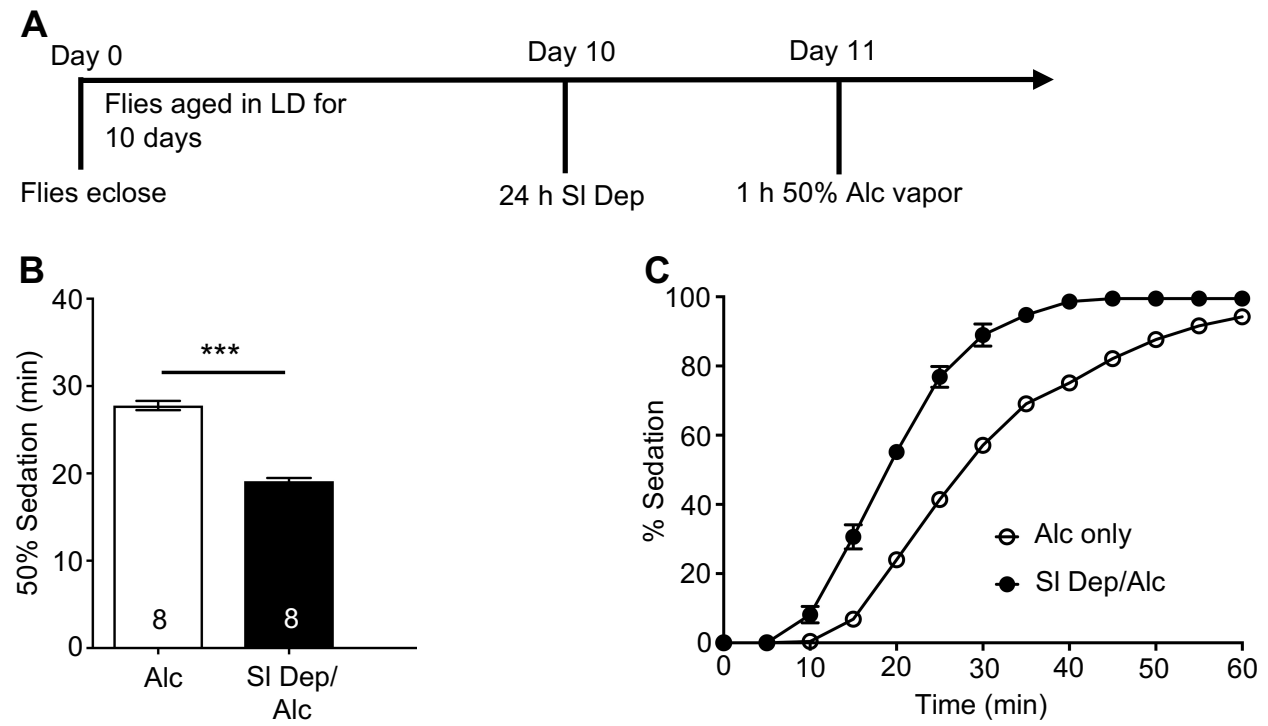

D

E
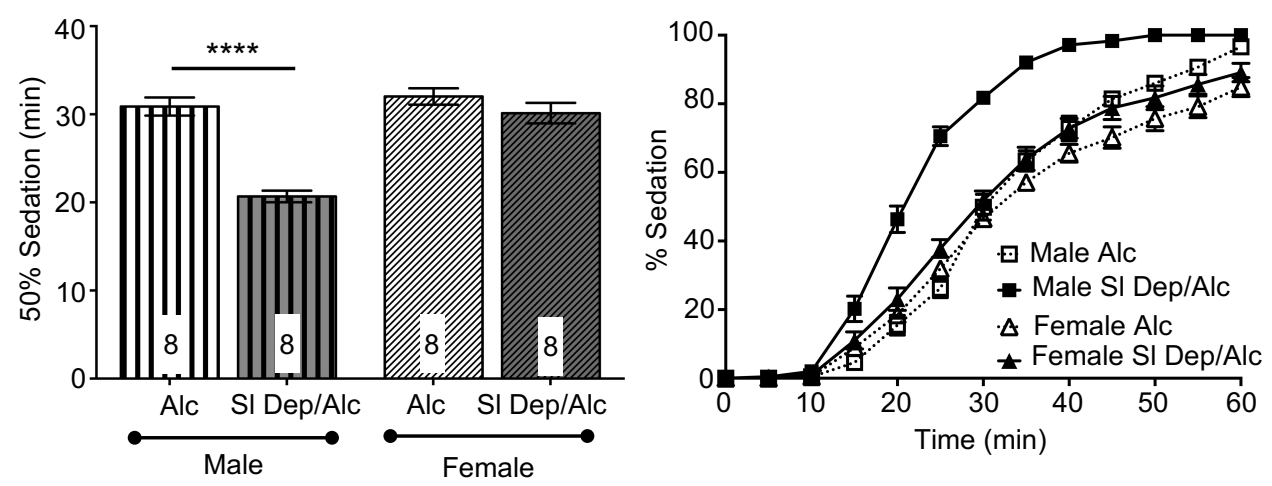

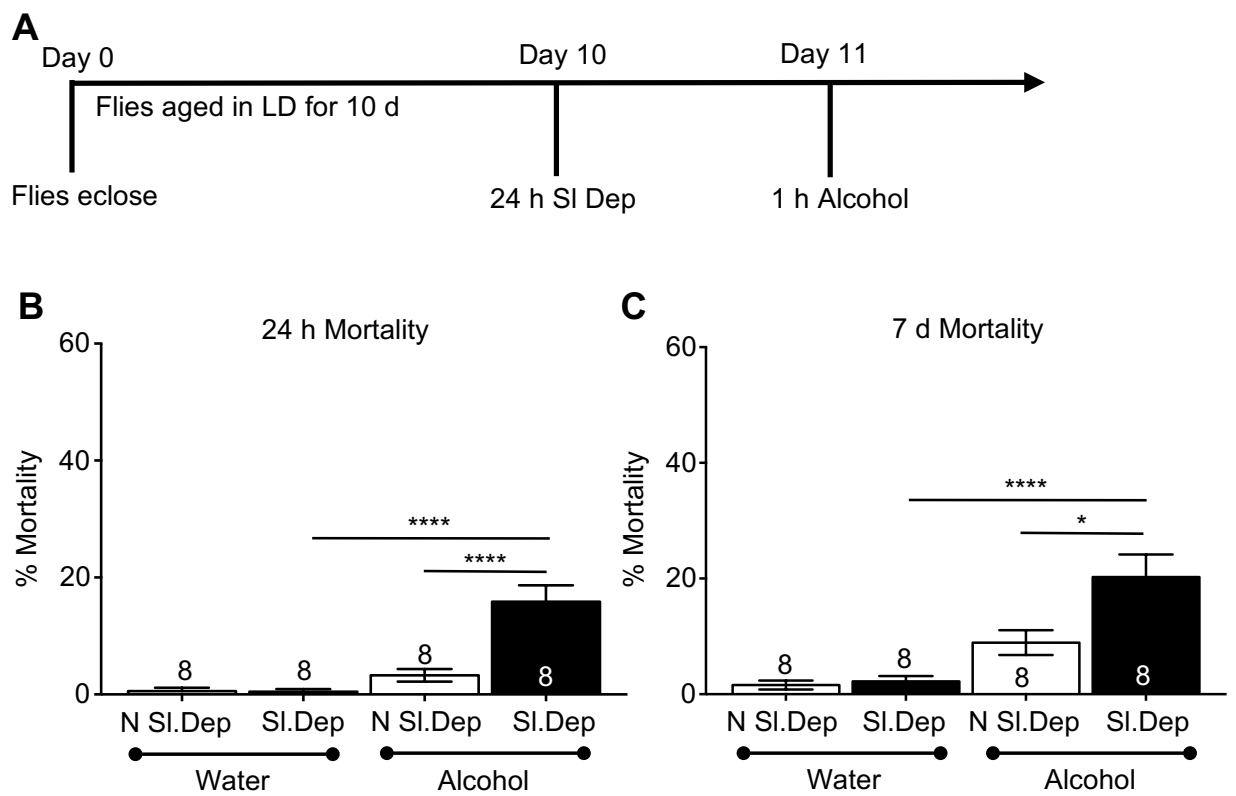

D

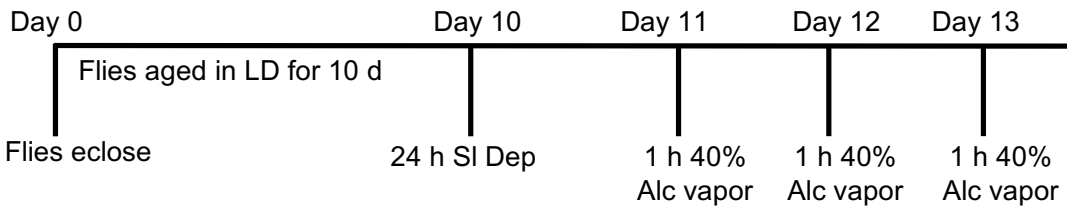

E

F
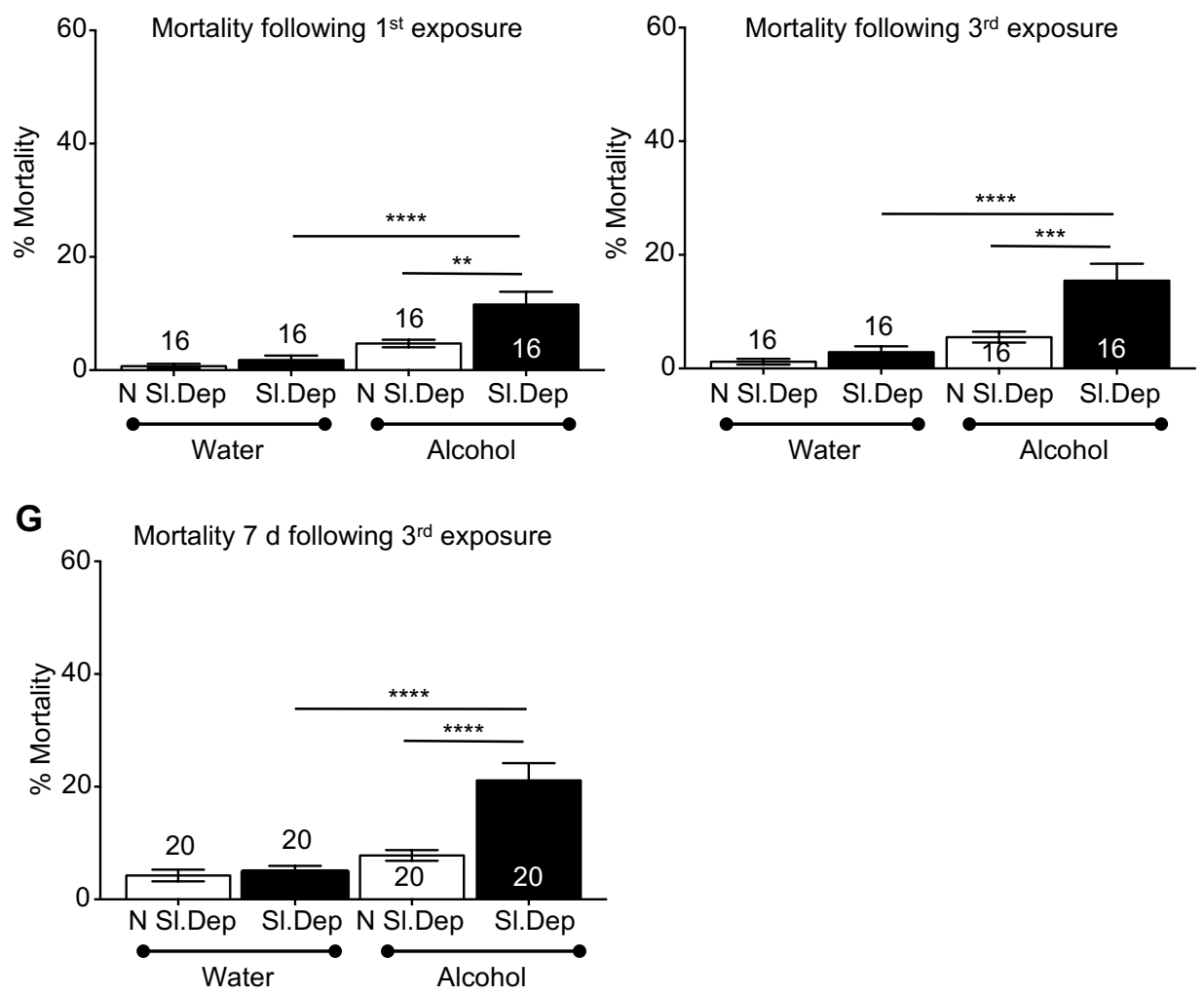

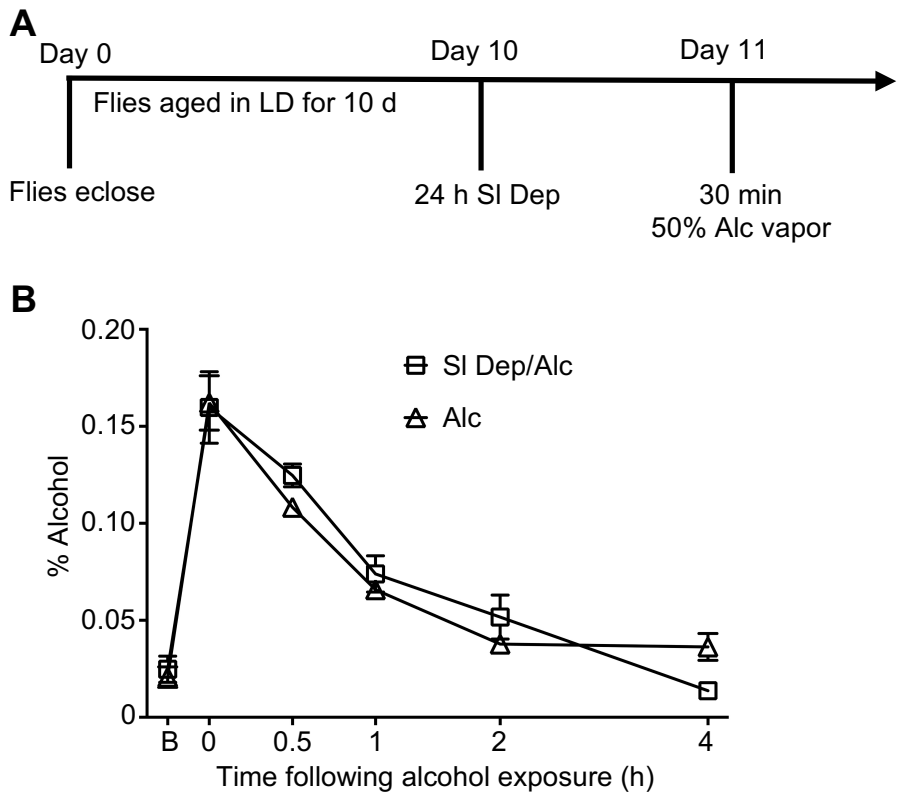


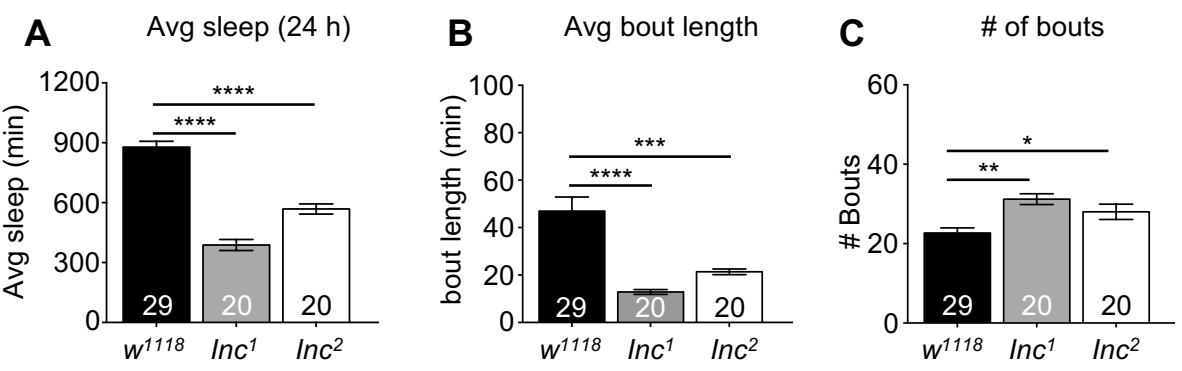

D
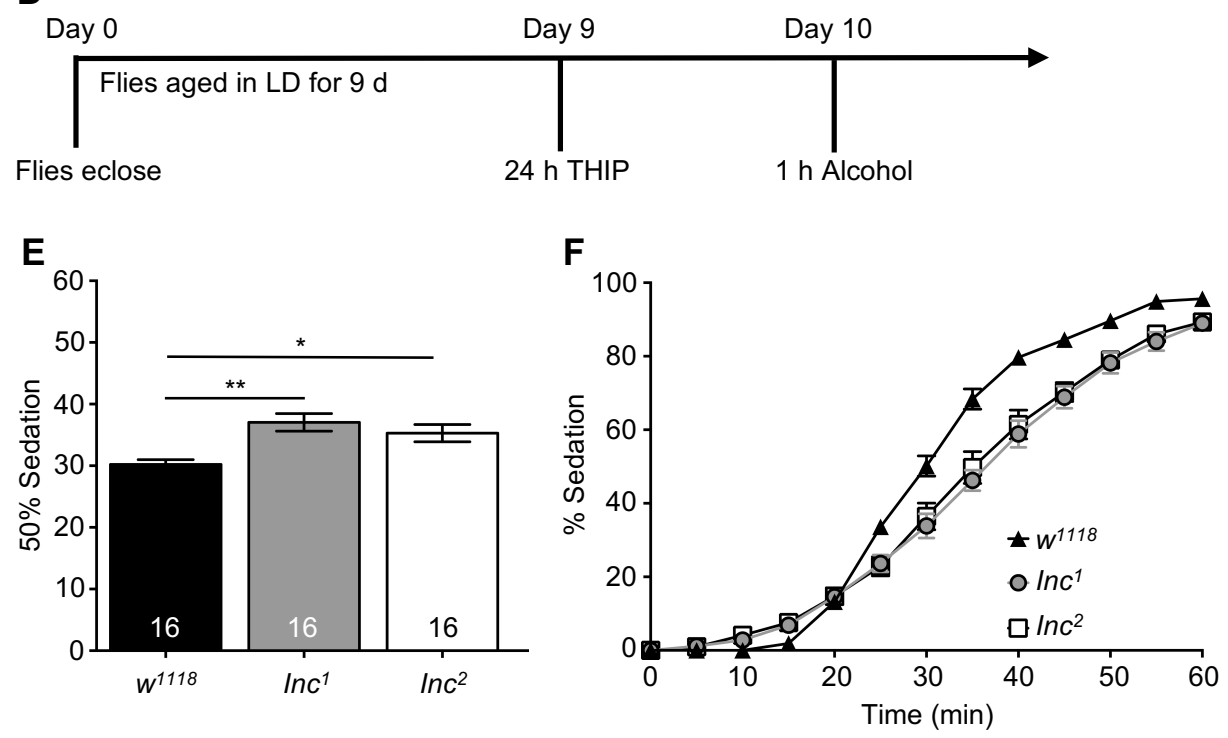
A
Day 0
Day 10

Flies aged in LD for $10 \mathrm{~d}$

Flies eclose

$1 \mathrm{~h}$ Alcohol

B 24 h Mortality (10 d)

C $\quad 7$ d Mortality (10 d)
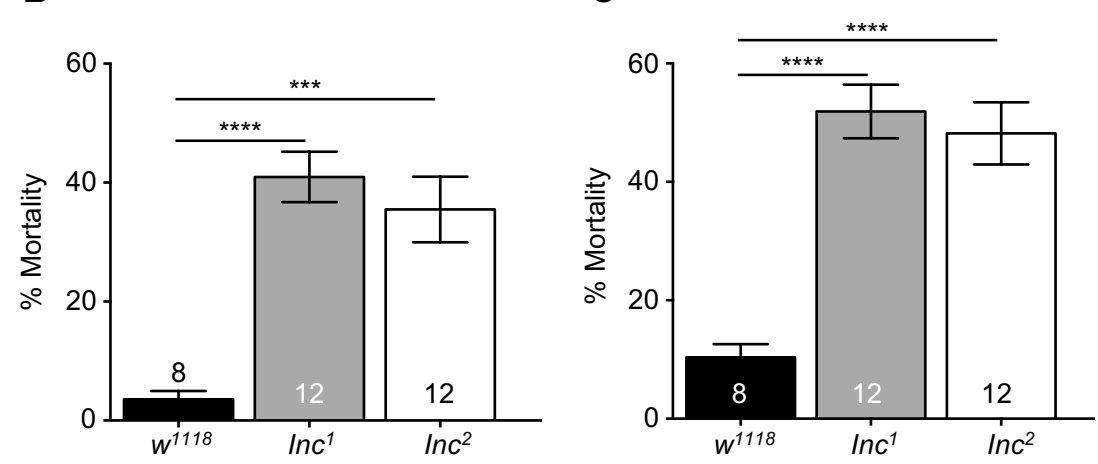

D

Day 0

Day 3

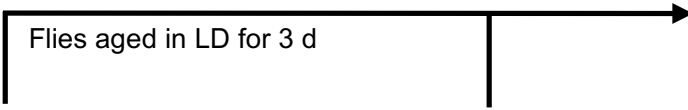

Flies eclose

$1 \mathrm{~h}$ Alcohol
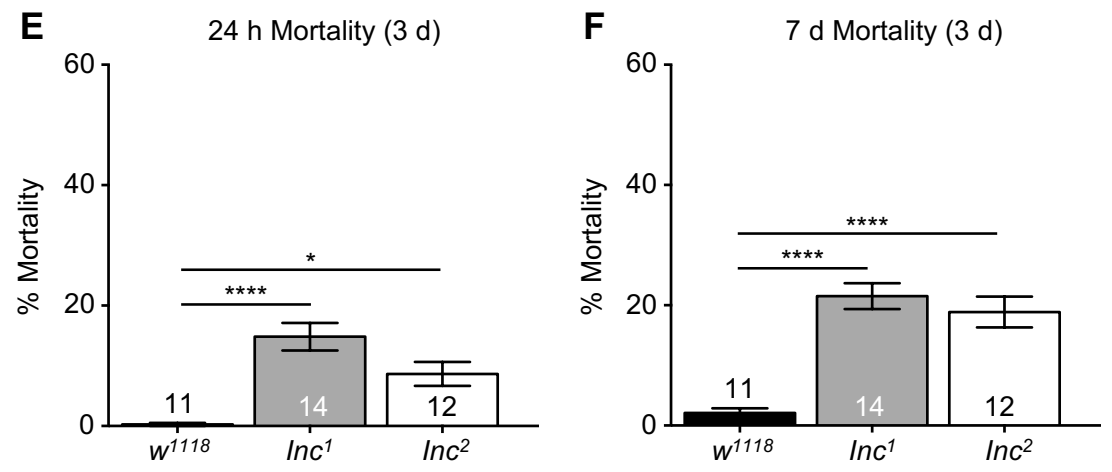


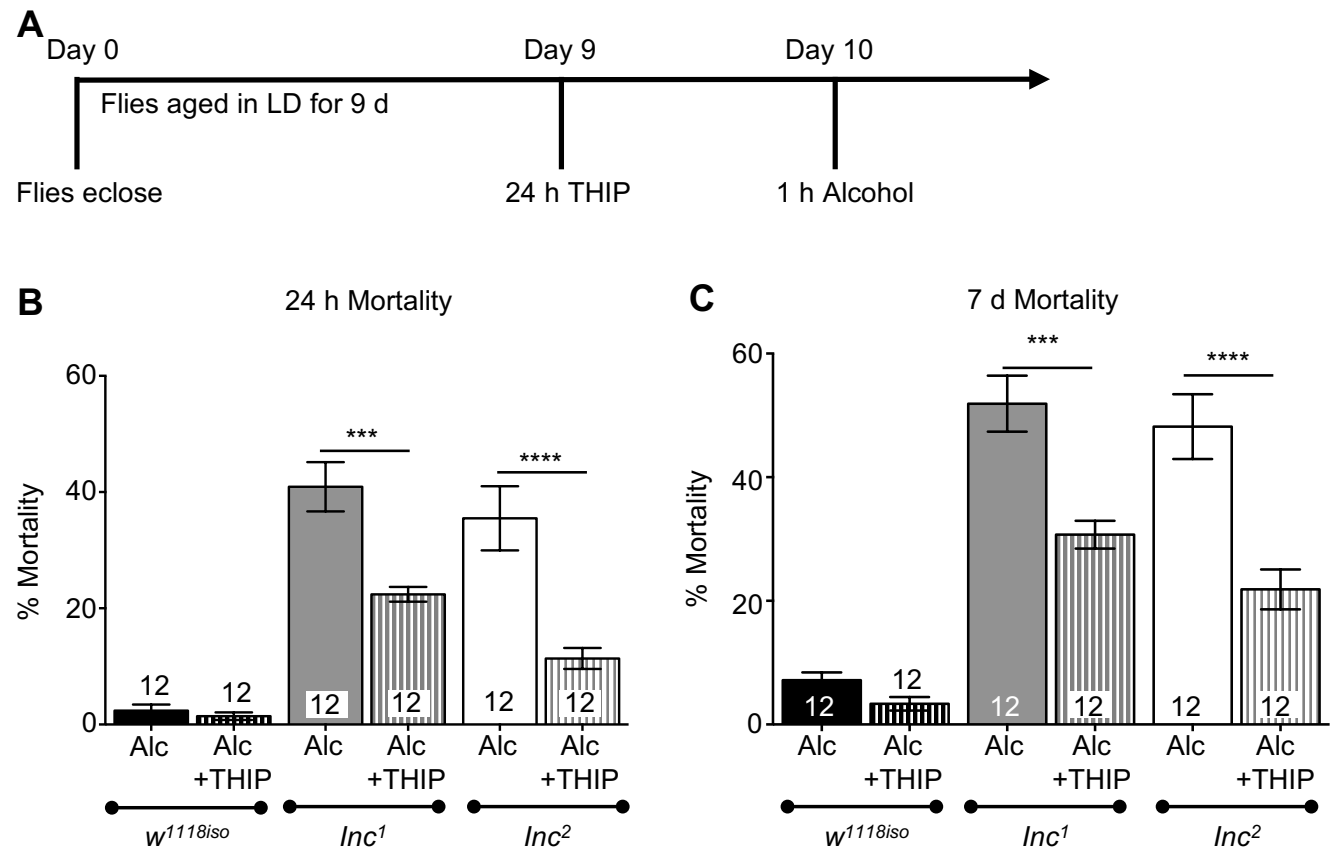

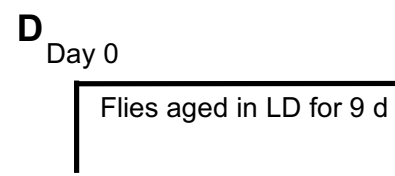

Flies eclose

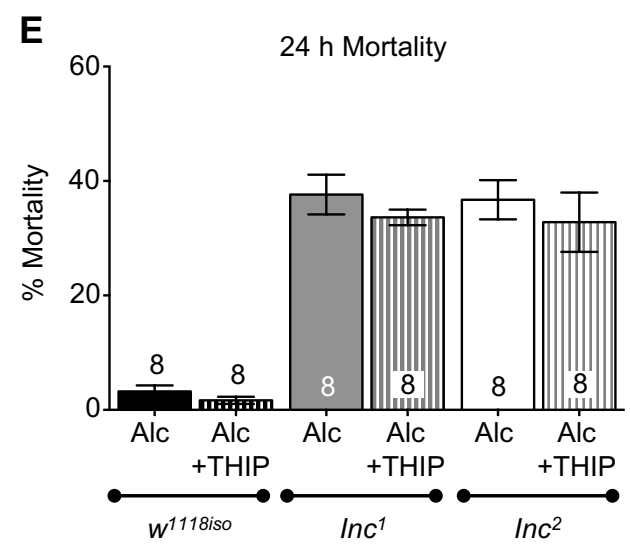

Day 10, ZT7

Day 10, ZT9

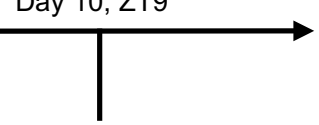

$1 \mathrm{~h}$ Alcohol

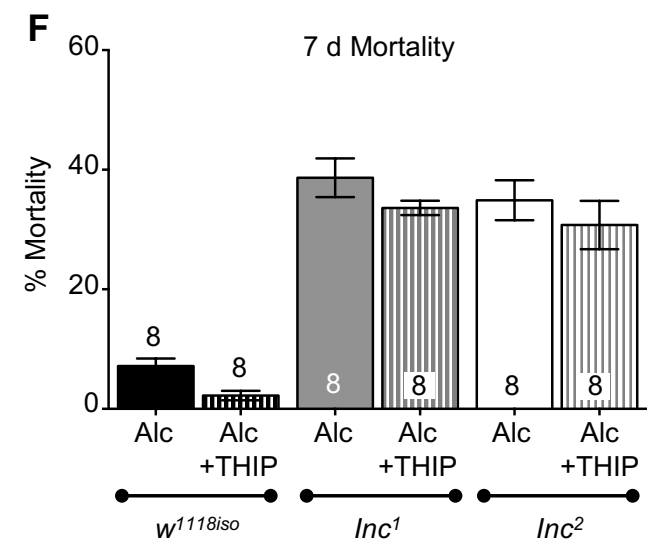


A Sleep $(24 \mathrm{~h}) \quad$ B
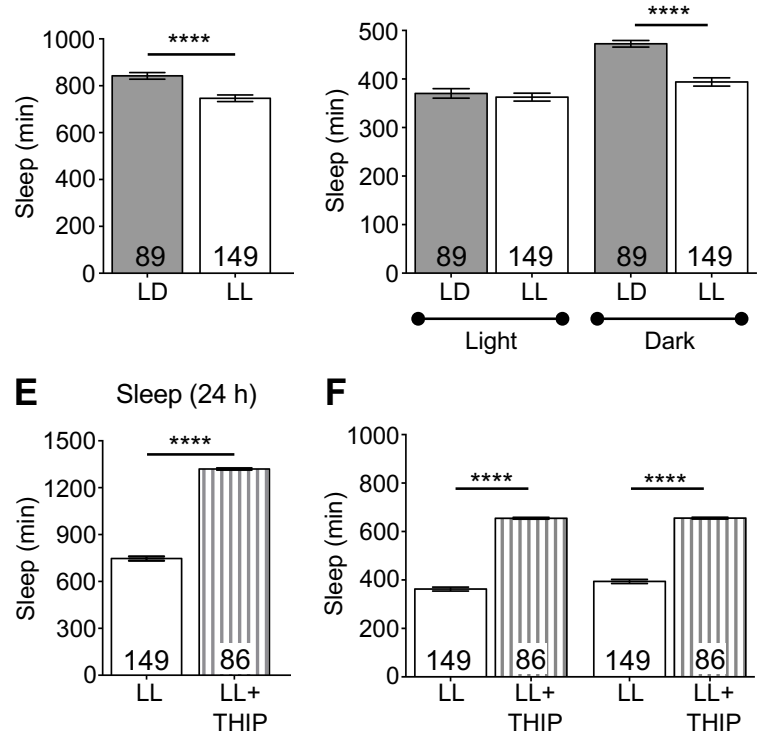

\section{F}

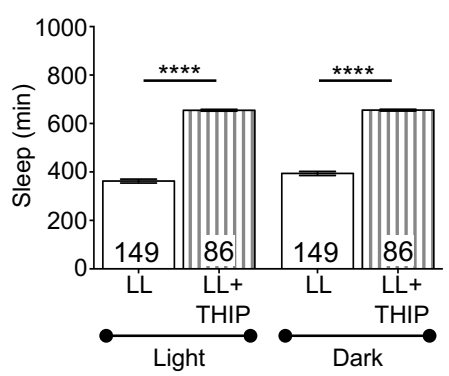

C

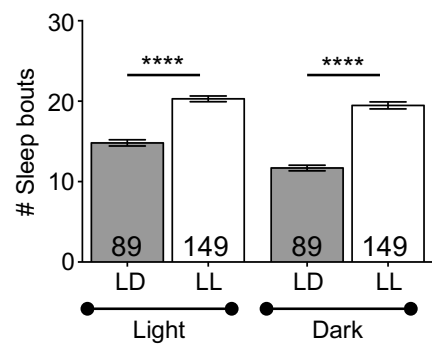

G

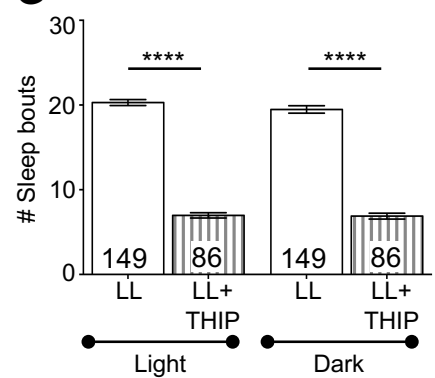

D

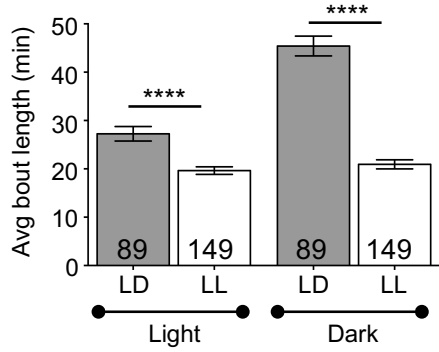

H

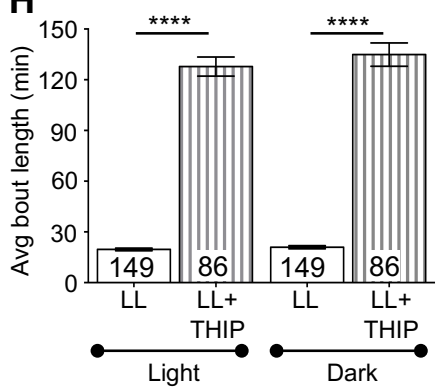

D

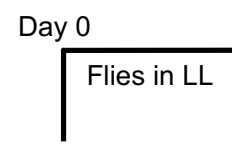

Flies eclose
Day 8

Day 10

Day 11 Day 12

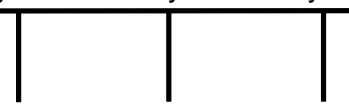

Flies on $0.1 \mathrm{mg} / \mathrm{mL}$ THIP for $48 \mathrm{~h}$ Alc vapor Alc vapor

Alc vapor
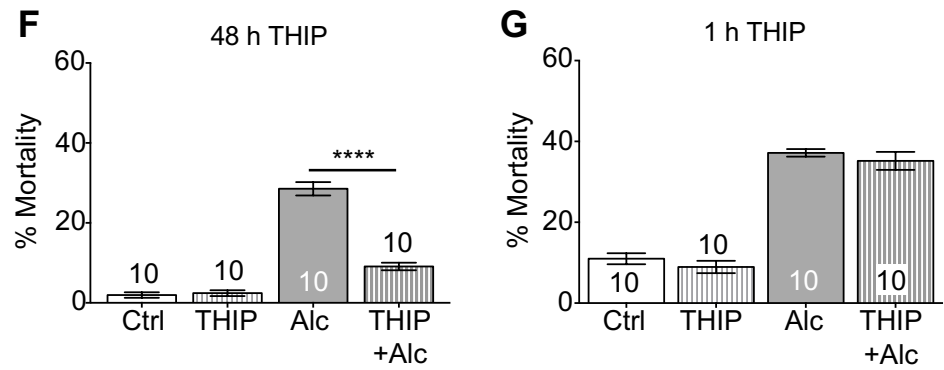

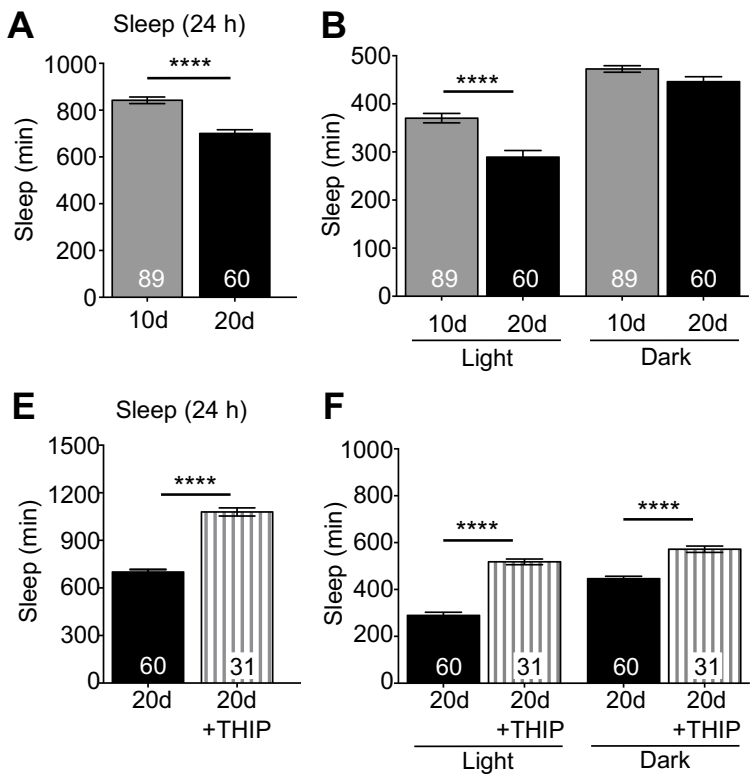

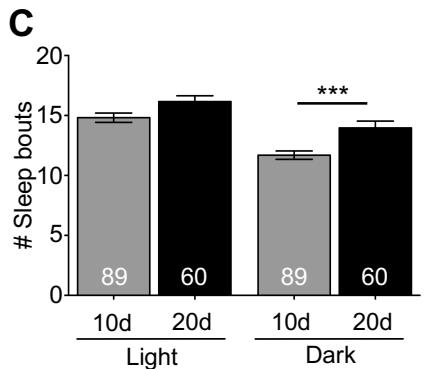

\section{G}

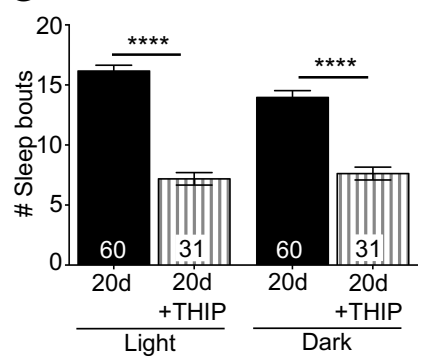

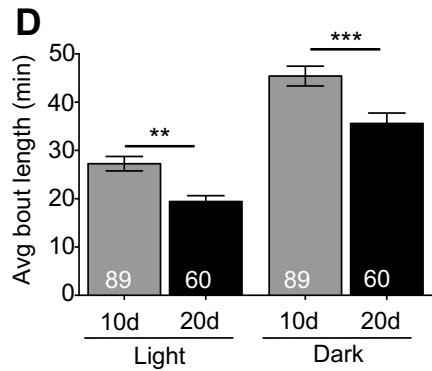

H

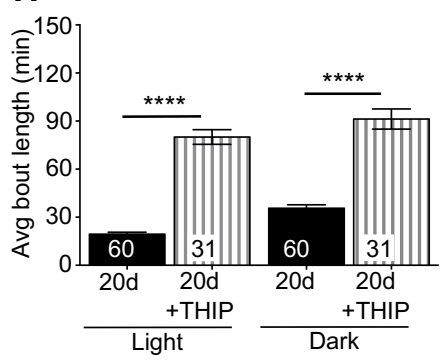

I
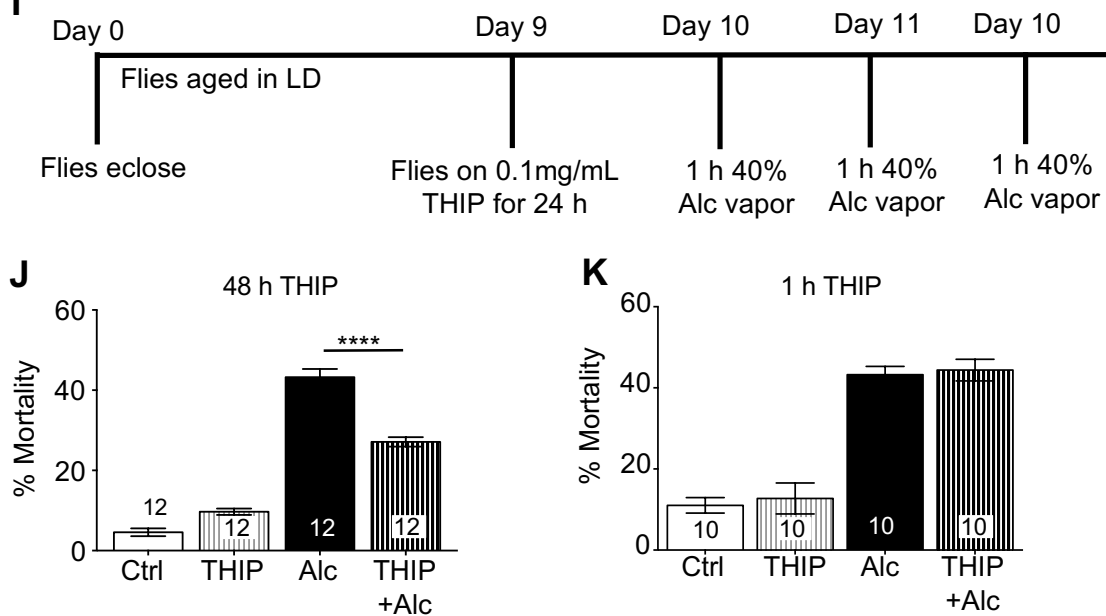
A

Day 0

Day 10

Day 11

Flies aged in LD for $10 \mathrm{~d}$

Flies eclose

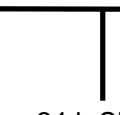

24 h SI Dep
$4 \mathrm{~h}$

Pre-exposure

$30 \mathrm{~min} 50 \%$ Alc vapor est

1 h $50 \%$ Alc vapor
B

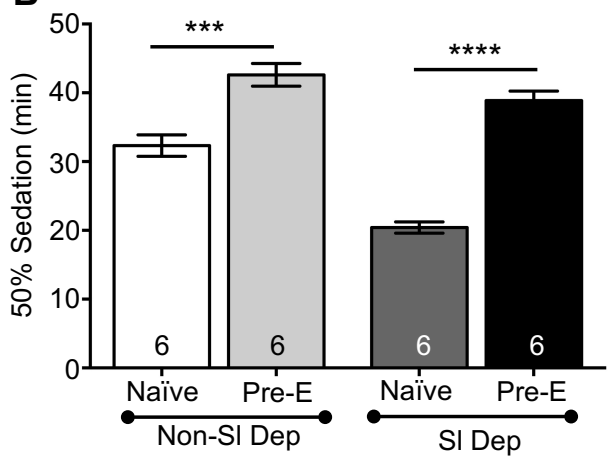

C

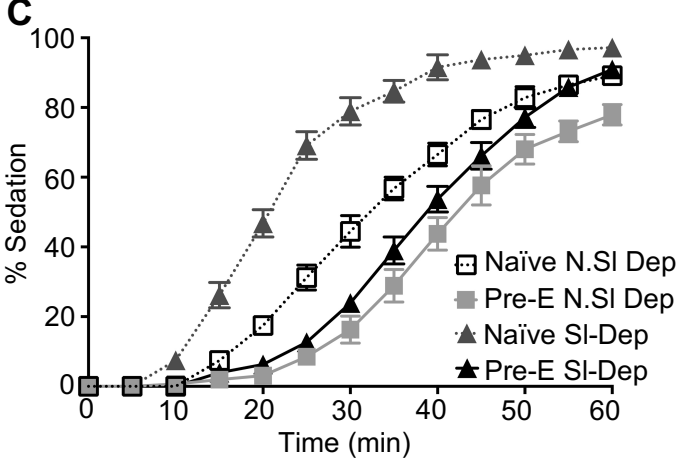

D

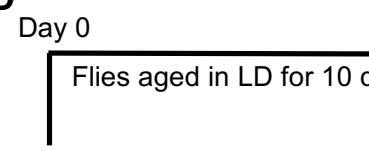

Flies eclose
Day 10

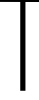

24 h SI Dep
Day 11

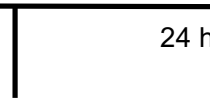

Pre-exposure

30 min 50\% Alc vapor
Day 12

$24 \mathrm{~h}$

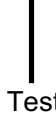

Test

1 h $50 \%$ Alc vapor
E

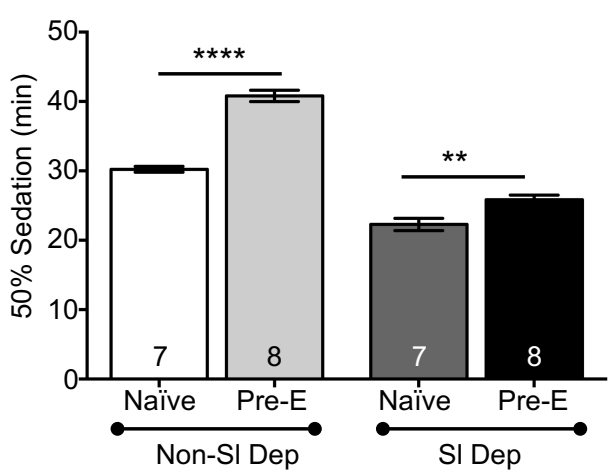

G

Flies eclose

Day 10

F

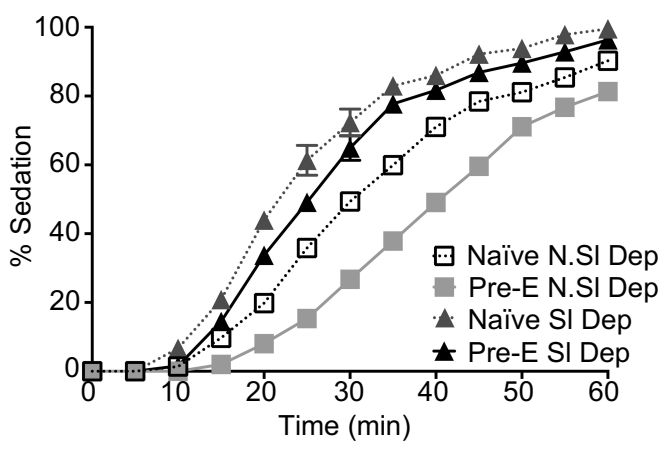

Day 0

Flies aged in LD for $10 \mathrm{~d}$

24 h SI Dep

H
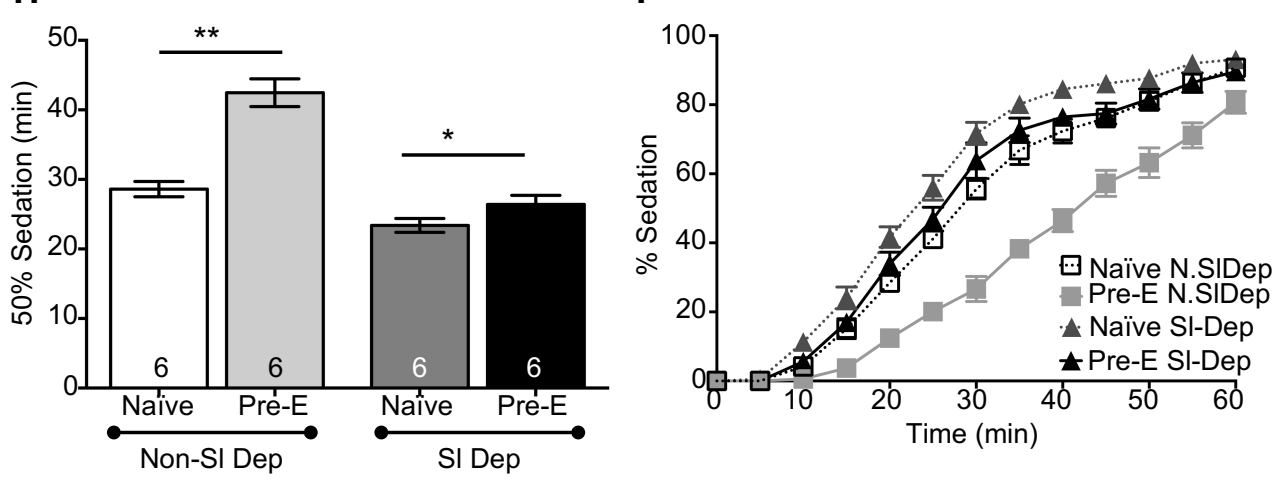